\title{
Does It Matter Where You Came From? Ancestry Composition and Economic Performance of US Counties, 1850-2010
}

\author{
Scott L. Fulford, Ivan Petkov, and Fabio Schiantarelli*
}

\begin{abstract}
April 2020
Abstract

What impact on local development do immigrants and their descendants have in the short and long term? The answer depends on the attributes they bring with them, what they pass on to their children, and how they interact with other groups. We develop the first measures of the country-of-ancestry composition and of GDP per worker for US counties from 1850 to 2010 . We show that changes in ancestry composition are associated with changes in local economic development. We use the long panel and several instrumental variables strategies in an effort to assess different ancestry groups' effect on county GDP per worker. Groups from countries with higher economic development, with cultural traits that favor cooperation, and with a long history of a centralized state have a greater positive impact on county GDP per worker. Ancestry diversity is positively related to county GDP per worker, while diversity in origin-country economic development or culture is negatively related.
\end{abstract}

JEL classification: J15, N31, N32, O10, Z10

Keywords: Immigration, Ethnicity, Ancestry, Economic Development, Culture, Institutions, Human Capital

* Scott Fulford: Consumer Financial Protection Bureau, email: scott.fulford@cfpb.gov. The views expressed in this paper are those of the authors and do not necessarily represent the views of the CFPB or the United States. Most of this work was completed while Scott Fulford was on the faculty at Boston College. Ivan Petkov: Northeastern University, email: i.petkov@ northeastern.edu. Fabio Schiantarelli: Boston College, email: schianta@bc.edu. The authors of this paper are a descendant of the Great Puritan Migration, a first-generation Bulgarian, and a first-generation Italian. We would like to thank Ethan Struby, Lauren Hoehn Velasco, and Ana Lariau Bolentini for their excellent research help, and Andrew Copland and Hayley Huffman for their editorial assistance. This work benefited greatly from the comments of participants in the Boston College Macroeconomics Lunch, the Harvard University Economic History Seminar, seminars at the University of Delaware, the College of the Holy Cross,, the EIEF, and EAP OECD, and the Brown University "Deeply Rooted Factors in Comparative Development" Conference, the 2015 Barcelona Summer GSE forum, the 50th Anniversary Essex University Economics Conference, and the NBER 2015 Political Economy Summer Institute. In addition, we gratefully acknowledge useful conversations with and suggestions from Alberto Alesina, Oded Galor, Nathan Nunn, Luigi Pascalli, Enrico Spolaore, Francesco Trebbi, and David Weil. We also thank the editor and referees for very useful comments, suggestions, and guidance. 


\section{Introduction}

What impact do immigrants and their descendants have in their new homes in the short and long term? The answer depends on the attributes they bring with them, what they pass on to their children, and how they interact with other groups. When people move to a new place, they leave behind the complex interactions of institutions, culture, and geography that determine economic outcomes in their homeland. They bring with them their own human capital and their cultural values, norms, and knowledge and experience of institutions. These values and experiences help shape the way they interact with others, the institutions they form in their new home, and their incentives for investing in human and physical capital. Because immigrants pass on many traits to their children, the effects of immigration do not end in the first generation and they may become even more important as new groups change the society around them. ${ }^{1}$

This paper uses the large and diverse migration to and within the United States over a century and a half to study the effect of the changing ancestry mix on local economic development. The United States constitutes an ideal laboratory to address this issue because of the large immigration flows from many countries that characterize its history (Daniels, 2002, pp. 24-25). These immigrants came to the United States from different parts of the world with diverse histories and cultures. Some were brought against their will as slaves; others decided to come for economic reasons, or seeking religious or political freedom. Once here, the immigrants and their descendants had to negotiate economic, cultural, and institutional relationships with other groups who were there before them or settled after them.

To perform our analysis, we build two unique new data sets. Using individual records from the US census going back to 1850 , we construct the country-of-ancestry composition of each US county's population. Crucially, we produce an objective measure of the ancestry composition of

\footnotetext{
${ }^{1} \mathrm{~A}$ substantial body of research has shown the persistence of cultural traits between the first and second generation of immigrants. See the reviews by Fernández (2010) and Bisin and Verdier (2011) of the empirical and theoretical literature on cultural transmission. Among recent theoretical contributions see Doepke and Zilibotti (2017). Beyond the second generation, the persistence varies across cultural attitudes and countries of origin, but even for faster moving traits, differences remain by the fourth generation (Giavazzi, Petkov, and Schiantarelli, 2019). See also Abramitzky, Boustan, and Eriksson (2020) on differences in the pace of name-based assimilation by country of origin.
} 
the full population, not just of first-generation immigrants, and so we are able to capture the longterm impact of groups and their descendants as they come to the US and move within it. ${ }^{2}$ Second, we create a more comprehensive measure of the GDP of each county going back to 1850 that includes agriculture, manufacturing, and services. While measures of manufacturing output and intermediate inputs and agricultural output have been available at the county level, we construct measures of value added for both sectors. More importantly, focusing only on manufacturing and agriculture overlooks the large and growing contribution of the service sector, and so undervalues urban areas and misses the important and changing role played by the transportation, distribution, and financial sectors.

We address three central questions: Do ancestry groups have different effects on local development? If so, which characteristics brought from the country of origin explain why groups have different effects? As groups come together and interact, what is the impact of ancestry diversity? Importantly, we focus on whether the mix of ancestries matters, not the impact of increased total population from immigration or internal population growth. Our work shows that (1) groups have different economic impacts, (2) these impacts are closely related to characteristics in the origin country, and (3) that overall diversity has both positive and negative consequences, depending on the form of diversity.

To help separate the economic effects of people and what they bring with them from the economic effects of a place's characteristics we take several approaches that deal with distinct problems. First, our long panel allows us to control for unobservable county characteristics and hence separate out the effects of the evolving ancestry composition from time invariant characteristics of a county. Doing so removes the endogeneity that arises if certain ancestry groups are attracted to places with particular characteristics. We show that not controlling for the these fixed characteristics leads to misleading conclusions about the effect of the endowment characteristics brought by immigrants from the origin country.

This time-invariant type of endogeneity is not the only problem that must be addressed if one

\footnotetext{
${ }^{2}$ Note that we do not rely on self-reported ethnicity — available only since 1980—which also reflects the evolving nature of ethnic identity as a social construct.
} 
wants to make causal statements about the effect of ancestry composition on local development. It is also possible that ancestry groups with particular endowments are more willing to move in response to short-term county-specific economic shocks, creating a form of short-term reverse causality. We address this potential additional source of endogeneity using three instrumental variables approaches. The conclusions we arrive at when instrumenting under each approach are similar to each other. They are also similar to the conclusions basedon estimates obtained without instrumenting, suggesting that the biases arising from group-specific endogenous migration in response to shocks are a lesser concern compared to the importance of controlling for time-invariant county characteristics.

First, we create an instrument for each county's share of a given ancestry using the share in the past and growth in that ancestry nationally, excluding the county's state. ${ }^{3}$ Doing so removes any county-ancestry specific pull factors.

Second, we build an instrument for ancestry share using the the interaction of immigrant arrival times with the development of the railroad and highway transportation network that builds on Sequeira, Nunn, and Qian (2019). Because immigrant groups arrived at different times, groups were exposed to different transportation networks, so decided to go to different places for reasons that depend in large part on when they moved. We discuss how one can isolate from this information county-ancestry level variation that can be treated as exogenous, as it is unlikely to be related to group characteristics that may lead a particular ancestry to move disproportionately to a given county following a shock to local development opportunities.

Finally, we present dynamic panel GMM results (Holtz-Eakin, Newey, and Rosen, 1988; Arellano and Bond, 1991) that rely on appropriately lagged values of the regressors as instruments and address the potential issue of the Nickell (1981) bias when the time dimension of the panel is short. At their core, both the first approach and the GMM approach rely on the past distribution of ancestries. Because the vast majority of the population does not move from decade to decade,

\footnotetext{
${ }^{3}$ The use as an instrument of the past spatial distribution of immigrants, often adjusted for the national growth rate, has been a common strategy in the immigration literature. See Card (2001) and more recently Peri (2012), among others. See also Bartik (1991) in the local development literature. For details on our instrumenting strategy see Section 5.3.2.
} 
the ancestry distribution in one decade is highly predictive of the distribution in the next, so these instruments have highly predictive first stages. Of course, the validity of these instruments relies on the past shares being uncorrelated with current shocks. We are thus careful to use this approach only in dynamic models where we can test for-and reject-the presence of serial correlation in the error term. The instrument based on the interaction between immigrant arrival time and the railway and highway network is less dependent on the ancestry shares in the recent past and only uses the shares in 1870. It is comforting that the basic conclusions remain very similar across the three approaches.

We first show that ancestry groups have different effects on county GDP per worker, even after after we control for county-specific fixed effects, race, and other observables. The effects of different groups are correlated with characteristics of the country of origin. As a summary measure of what groups bring with them, we construct the average origin GDP per person in each county by weighting origin country GDP per person by the share of each ancestry in a county. When internal or external migration results in a county's residents coming from $1 \%$ higher GDP per person countries on average, county GDP per worker increases by $0.3 \%$ in the first decade and $0.6 \%$ in the long run. The impact grows over time, reaching its peak only after several decades. These effects do not seem to be related to origin-country inequality, suggestion that a model of self-selection, such as Borjas (1987), is not likely to be driving the results.

The relationship between origin GDP and county GDP per worker shows that there must be something important for economic development that is transportable and inheritable. We examine possible origin characteristics that might explain the relationship. What appears to matter most for local economic development are cultural characteristics that capture the ability of people to productively interact with others (Tabellini, 2010). Moreover, it also matters whether immigrants came from a country with a long history of a centralized state not subject to foreign domination (Bockstette, Chanda, and Putterman, 2002; Putterman and Weil, 2010). Origin political institutions that may change rapidly and may not be deeply embedded in the immigrants beliefs or values, such as constraints on executive power or political participation, are not important for the impact of 
immigrants once we control for their experience of a strong state. Over the long-term, the human capital of migrants is not significantly associated with local economic development once other endowments are controlled for, perhaps because public schooling reduces educational differences and schooling policies respond endogenously to immigration flows (Bandiera et al., 2019).

Diversity has both positive and negative effects. Immigrants and their descendants must interact with other groups from different backgrounds, and the full impact of immigration depends on these interactions. When ancestry diversity increases, so does GDP per worker. Despite the often negative views that greet new groups, more diversity is actually good for growth. Yet when groups have important cultural differences that may affect their ability to interact with others, diversity has a negative effect on local economic development. The results suggest that when groups have to share a place and work together, diversity is good, as long as there is a degree of agreement in terms of cultural values that facilitate exchange and production. We provide evidence that the positive effect of ancestry diversity on development is partly explained by the fact that greater ancestry fractionalization is associated with a richer menu of locally available skills. More diverse places can have greater specialization and returns from trade.

The structure of the paper is as follows: after discussing the relationship with the literature in Section 2, we describe the evolution of ancestry and its construction in Section 3 and describe the construction of county level GDP in Section 4; Section 5 contains the main results, Section 6 explores possible mechanisms, while Section 7 concludes.

\section{Relationship with the literature}

Our work focuses on the effect of the ancestry mix on local economic development in the short and long run and sits at the intersection of several different strands of research on the historical causes of development, on immigration, and on the effect of diversity on economic outcomes. To begin with, we contribute to the vast literature on the historical roots of economic development. ${ }^{4}$ Because some of the different potential factors evolve endogenously in a place, it is difficult to identify and

\footnotetext{
${ }^{4}$ The literature here is vast and cannot be adequately surveyed here. See the reviews by Acemoglu, Johnson, and Robinson (2005), Nunn (2009), Spolaore and Wacziarg (2013), and Alesina and Giuliano (2015).
} 
disentangle the fundamental causes of development. To deal with this problem, an important subset of the literature focuses on the impact of immigrants. In particular, we build on Putterman and Weil (2010) who reconstruct the share of a country's ancestors in 2000 who migrated from each origin since 1500. They conclude that adjusting for migration flows greatly enhances the ability of historical variables, such as the experience of early development or early institutions, to explain differences in current economic performance. Another strand of this literature examines the impact of European colonists and of the institutions or human capital they brought with them (Acemoglu, Johnson, and Robinson, 2001; Glaeser et al., 2004; Albouy, 2012; Easterly and Levine, 2016). The distinguishing feature in our work is the long panel which allows us to cleanly distinguish the effects of immigrants and of the attributes they carried with them from those of the places they move to. In addition, we analyze which endowments brought by immigrants affect economic performance in the long run, a difficult yet important task (Easterly and Levine, 2016). Our examination of inherited culture is related to that of Algan and Cahuc (2010), who use the trust of different cohorts and generation of migrants in the United States to instrument for the changing trust in the origin country and assess its effect on economic development. ${ }^{5}$ A distinguishing feature of our contribution is that we use the change of ancestry composition over time in US counties to identify the effect on local development of attributes brought from the country of origin. This is the novel source of variation that our instrumenting strategy uses to identify the effect of culture and institutions on economic development, accounting for the endogeneity of their evolution.

Our emphasis on the long-run economic effects of immigrants and their descendants distinguishes our work from the many contributions that focus on the experience of first-generation immigrants and their short-run effect on the labor market. ${ }^{6}$ In addressing the long term consequences of migration in the US, our work is complementary to the recent paper by Sequeira, Nunn, and

\footnotetext{
${ }^{5}$ On the importance of culture for economic outcomes see Guiso, Sapienza, and Zingales (2006), Guiso, Zingales, and Sapienza (2008) Tabellini (2010), Fernández (2010), Alesina and Giuliano (2015), and Bisin and Verdier (2011).

${ }^{6}$ The literature on the effect of immigration is vast; see Borjas (2014) for a review, as well as the work of Borjas (1994), Card (2001), Ottaviano and Peri (2012), and Peri (2012). See also Hatton and Williamson (1998), who provide evidence from the Age of Mass Migration and Abramitzky and Boustan (2017), who put more recent work on immigration into its historical context. Finally, Tabellini (2020) studies the political and economic effects on natives' employment and wages of variations inimmigration flows to US cities in the period between 1910 and 1930 induced by WWI and the Immigration Acts of the 1920s.
} 
Qian (2019), who analyze how immigration to the United States during the Age of Mass Migration affected the prosperity of counties in 2000 and to We differ fundamentally from their contribution, because we focus on the effect of changes in the mix of the ancestries rather than the effect of the total size of historical migratory flows. Our work is also related, albeit less closely, to Burchardi, Chaney, and Hassan (2018), who find that if a county has a larger stock of ancestry from a given country, it is more likely to have a foreign investment link with that country today. They focus on explaining bilateral investment links and do not assess the effect this has on county level development, which is the focus of our investigation.

Finally, our finding that diversity has both positive and negative effects contributes to the growing literature that examines ethnic diversity. A substantial body of work suggests that various forms of ethnic diversity hinder economic performance by impeding the diffusion of new ideas or by harming investment in public goods. ${ }^{7}$ Yet other work suggests diversity can have positive consequences. ${ }^{8}$ Our results support recent work that suggests group diversity by itself may be good because of the gains from trade and specialization associated with it, but there are negative consequences if groups differ along important dimensions such as culture (Desmet, Ortuño-Ortín, and Wacziarg, 2017) or income (Alesina, Michalopoulos, and Papaioannou, 2016). The advantage of our approach is that by using ancestry rather than ethnicity, which may be endogeneous (Michalopoulos, 2012), and a panel to examine changes in diversity, we can more cleanly separate out the positive and negative consequences of diversity. Moreover, we focus on the effects of changes in the stock of ancestries and not on those induced only by greater diversity of first-

\footnotetext{
${ }^{7}$ See Spolaore and Wacziarg (2009) on barriers to diffusion and Alesina, Baqir, and Easterly (1999), Miguel and Gugerty (2005), and Easterly and Levine (1997) on ethnicity and local public spending.

${ }^{8}$ Ashraf and Galor (2013) find that the relationship between genetic diversity and country-level economic development is nonlinear, first increasing, then decreasing, resulting in an interior optimum level of diversity. In Putterman and Weil (2010), the standard deviation of state history generated by the post-1500 population flows is positively related to the income of countries today. Ager and Brückner (2013) show that fractionalization of first-generation immigrants across counties in the United States from 1870 to 1920 is positively related to economic growth, while polarization is negatively related. Alesina, Harnoss, and Rapoport (2016), using recent immigration data for 195 countries, present evidence of a positive relationship between birthplace diversity of immigrants and output, TFP per capita, and innovation. Ottaviano and Peri (2006) find that increased first-generation immigrant diversity is good for wages across US cities between 1970 and 1990. Docquier et al. (2018), using a state level panel for 1960-2010, provide support for the existence of positive skill complementarities associated with the birthplace diversity of immigrants, although the gains depend on the cultural and economic distance of the immigrants.
} 
generation immigrants, as, for instance, in Ottaviano and Peri (2006), Ager and Brückner (2013), Alesina, Harnoss, and Rapoport (2016) and Docquier et al. (2018).

\section{Ancestry in the United States}

There have been immense changes in overall ancestry and its geographic distribution in the United States since 1850. In this section, we describe how we construct a measure of the geographic distribution of ancestry over time and briefly discuss its evolution. Our estimates are the first consistent estimates of the stock of ancestry over time for the United States at both the national and county level. They are constructed using the census micro-samples and keep track of internal migration and population growth, in addition to new immigrant flows. While previous work has examined racial groups and, in recent decades, some ethnic groups, our work is thus the first to be able to examine the full range of diversity in this nation of immigrants. Finally, our measure of ancestry is distinct from self-reported ethnicity available in the census since 1980, which also reflects the evolving nature of ethnic identity as a social construct.

\subsection{Constructing an ancestry measure}

We build our estimates of the ancestry shares at the county level and of their evolution over time by aggregating information from questions collected in the decadal census that ask every person to identify the state or country where he or she was born. For every individual, we use the available information to form her expected ancestral origin based on her birth place and, when available, on her parents' birth place. Aggregating over many individuals in given place forms a population estimate of the ancestry composition. For first generation immigrants born outside the United States, the expected ancestry is straightforward since we know exactly where they came from. This is also true for the children born in the US from first generation immigrants from 1880 to 1970 when we observe the birth place of a person's parents. If the parents come from two different countries, we assume that they contribute equally to the ancestry of their children. If the parents are born in the US, we assign the child the ancestry among the children under five in the parents' 
birth state, or in the child's residence county if the child has not moved states, in the closest census year to the child's birth. This method allows for some groups to have faster population growth than others past the second generation and keeps track of internal migration. Past the second generation, the ancestry share depends on the ancestry share in the past, since internal migrants bring their ancestry with them when they move from state to state and pass it on to their children. We proceed iteratively, starting with the first available individual census information in 1850 and using the first census in 1790 updated with immigration records as the initial distribution. The online appendix A gives the full details on the construction of ancestry and on the sources used.

Accumulating this information over time for a geographic area gives, in expectation, the fraction of the people in a given area whose ancestors come from a given country. We therefore capture not just the fraction of first-generation immigrants, but keep track of the ancestry of everyone, accounting for internal migration, the age structure of the population, differential population growth across ancestries, and local variations in the counties where people from different countries originally settled.

We can construct ancestry at the county level until 1940. Starting in 1950, the census reports data only for somewhat larger county groups, whose definition changes slightly over time. Because of this aggregation, our analysis centers on the 1154 county groups that allow us to maintain a consistent geographical unit of analysis from 1850 to 2010 . We continue to use county to refer to county groups, except where the specific number of groups is important.

The county or county group is the smallest unit for which this sort of demographic accounting can be done and makes sense. The county is also a useful unit because it is the only consistent sub-state administrative district. While the exact powers held by counties vary somewhat by state, counties are generally judicial and police districts with the county sheriff as the top law enforcement official. Many infrastructure and transportation decisions are also made at the county level. In addition, all local decisions are made at the county level or within the county, because counties contain cities, towns, and education districts that decide even more local matters. ${ }^{9}$ Therefore,

\footnotetext{
${ }^{9}$ For a description of the role of counties, see the National Association of Counties http://www. naco. org/ sites/default/files/documents/Counties-Matter.pdf, accessed 1 August 2017.
} 
if ancestry affects individual outcomes, local goods, or has externalities that relate to in-person interactions an analysis at the county level will allow us to capture them.

Because the contributions of African Americans and the legacy of slavery are so central to understanding ancestry in the United States, our analysis gives a special treatment to race. The census has recorded racial characteristics since 1850, and we use it to form separate ancestries for African Americans and Native Americans. We allow for distinct ancestries within racial groups when the information is available, and so recent Nigerian immigrants or immigrants from the West Indies, for instance, are treated as distinct from African Americans who are descendants of former slaves. We emphasize that any finding we make regarding African Americans cannot distinguish African culture and institutions from the brutal history of slavery and the cultural, economic, and political repression that continued for more than a century following the Civil War.

Our approach has many unique advantages, but cannot cleanly answer some questions. While nativity was a central concern in the early censuses, other distinctions within country of origin, such as religion or regional origin, were not generally or consistently recorded. Therefore, we cannot distinguish sub-national groups, even though the distinctions between them may be very important. For example, many Russian immigrants were Jewish, but since we cannot distinguish these immigrants, all Russians are recorded as a single group. Similarly, the census does not identify the African origin countries of the slave population in 1850. In addition, our procedure does not distinguish between counties with a great deal of intermarriage and those with little if both have the same overall ancestry share at a county level.

While ancestry, as we define it, is objective, ethnicity and race are to a large extent social constructs (Nagel, 1994). The concept of ethnicity is continually evolving as groups define themselves and are defined by other groups. Ethnicity not only changes over time, but it may not be the same concept across the country at a given time. The social construction of ethnicity does not make it any less powerful, but it is necessarily an endogenous and fluid measure that responds to circumstances. Ancestry appears to be the primary input in forming ethnicity (Waters, 1990), and so we would expect the two to be highly related. Indeed, our measure of ancestry predicts 
Figure 1: Ancestry share in the United States: 1870, 1920, 1970, and 2010

Share in 1870 (percent)



Share in 1970 (percent)

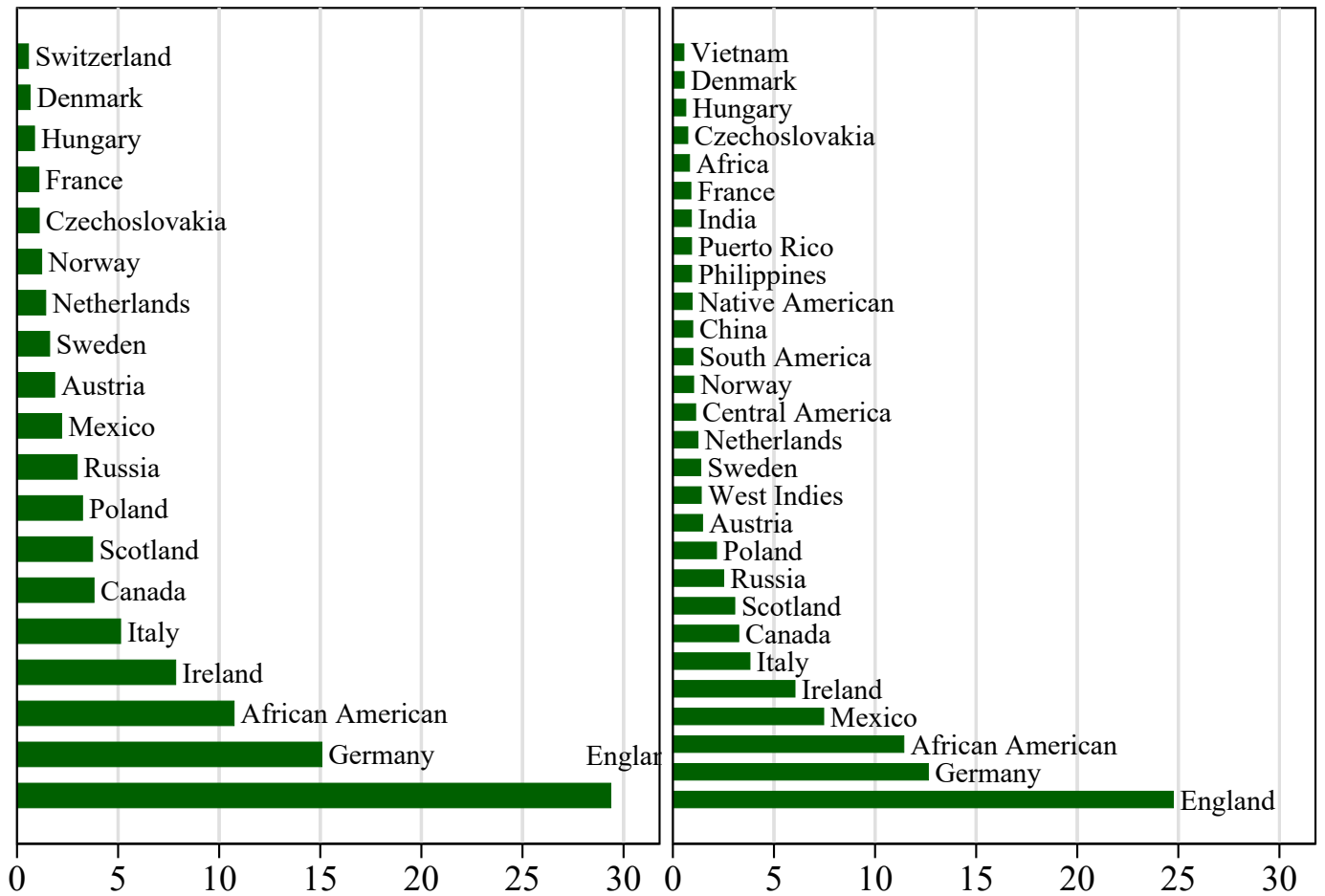

Share in 1920 (percent)

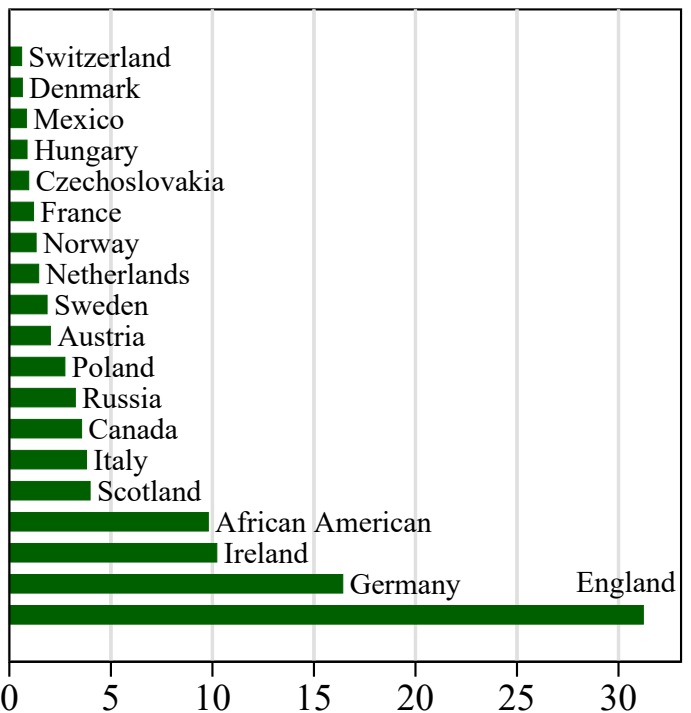

Share in 2010 (percent)

This figure shows aggregate ancestry shares in the United States for ancestries with greater that $0.5 \%$ of the population. Ancestry shares are created by summing the share in each county weighted by county population in each year. See Section 3 and the online appendix A for the ancestry construction. 
the self-reported ethnicity or ancestry in the 2000 census very well. For instance, the the overall correlation coefficient for all ancestries across counties in 2000 is 0.966 (see the online appendix A.5and Table A-1 where we also report the cross county correlation for each ancestry separately). In Figure A-1 in the the online appendix we report the share of the total population of the US for each ancestry based on our measure and self-reported ancestry in the 2000 census. We closely match the shares. ${ }^{10}$

\subsection{Ancestry since 1850}

American ancestry has become increasingly diverse over time, and we provide a brief description here of the overall trends in composition necessary to understand our results. Figure 1 illustrates this growing diversity by showing the share of the ancestry stock for all groups that make up more than $0.5 \%$ of the population for $1870,1920,1970$, and 2010. One important finding from our work is that the United States has not had a single majority group since 1870, when waves of German and then Irish immigration finally pushed the English below $50 \%$.

Starting in the 1870s, successive waves of immigration rapidly transformed the ancestral makeup of the United States. Older ancestral groups were still expanding, but not nearly as fast as the newer groups, and so, in a relative sense, the older groups declined substantially in importance. The share of descendants from England fell continuously and rapidly until the 1920s. The new immigrants were diverse, with large groups from coming from Southern Europe (particularly Italy), eastern Europe (particularly Poland and Russia), northern and central Europe, including the Austrians and Germans, and from Scandinavian countries.

Immigration restrictions that started in the 1920s severely slowed immigration until the 1960s. These restrictions were only gradually relaxed, and so changes during this period mostly represent internal differences in population growth and demographic structure. Beginning in the 1960s, new groups from Mexico, Central America, and South America started to arrive. The share of

\footnotetext{
${ }^{10}$ Even the places where we do not match exactly are illuminating. The dots in the upper left are variations of "Southern Europe, Not Specified" or "Baltic States, Not Specified." While these birthplaces have generally been valid responses, because we built up our ancestry measure from the actual birthplace of a migrant or her parents, we are far more likely to classify someone to a particular country, so put a smaller share in these generic ancestries.
} 
Mexican descendants in Figure 1 grew substantially between 1970 and 2010. A large number of immigrants from Asia arrived as well. By 2010, the United States had become much more diverse in origin, with substantial populations from countries in Asia, Europe, Africa, and Central and South America. In 2010, descendants of immigrants from England represented just $25 \%$ of the population, followed by people of German (12.6\%), African American (11.4\%), Mexican (7.4\%), Irish (6\%), and Italian (3.8\%) ancestry.

The maps in Figures 2 and 3 show where the largest groups settled and moved over the years. They indicate a tendency to spread out over time, although the geographical and time dimensions of the spreading differ by group. For example, the Germans arrived early, started in a few areas around Milwaukee, Pennsylvania, and Texas, and subsequently spread to the entire Midwest and West. The Irish, followed, and while initially concentrated in the cities of the Northeast, dispersed widely throughout the entire United States. Italians came later, initially settled mostly in New York and Boston, and eventually spread throughout the Northeast but not far beyond, except for a presence in California and around New Orleans. The Great Migration of African Americans from the South to the cities throughout the country can be clearly seen by comparing 1920 in Figure 2 to 1970 in Figure 3. Because the maps do not depict cities well, the importance of the Great Migration is less visually obvious. That said, African Americans are still highly concentrated geographically. Finally, the maps show the diffusion of people of Mexican ancestry from the border regions of the Southwest to other areas of the country. The heterogeneity in time and space in the way ancestries spread provides us with the main source of identification to assess the effect on local development of immigrant attributes.

\section{County GDP from 1850-2010}

To understand the impact of ancestry on economic performance, we construct a county-level measure of GDP per worker. Starting in 1950, the decennial census began measuring income at the county level. Before then, it recorded county-level information only on manufacturing output and intermediate inputs and agricultural output. The main challenge is to provide an estimate of county 
Figure 2: Select ancestries in the United States: 1870 and 1920
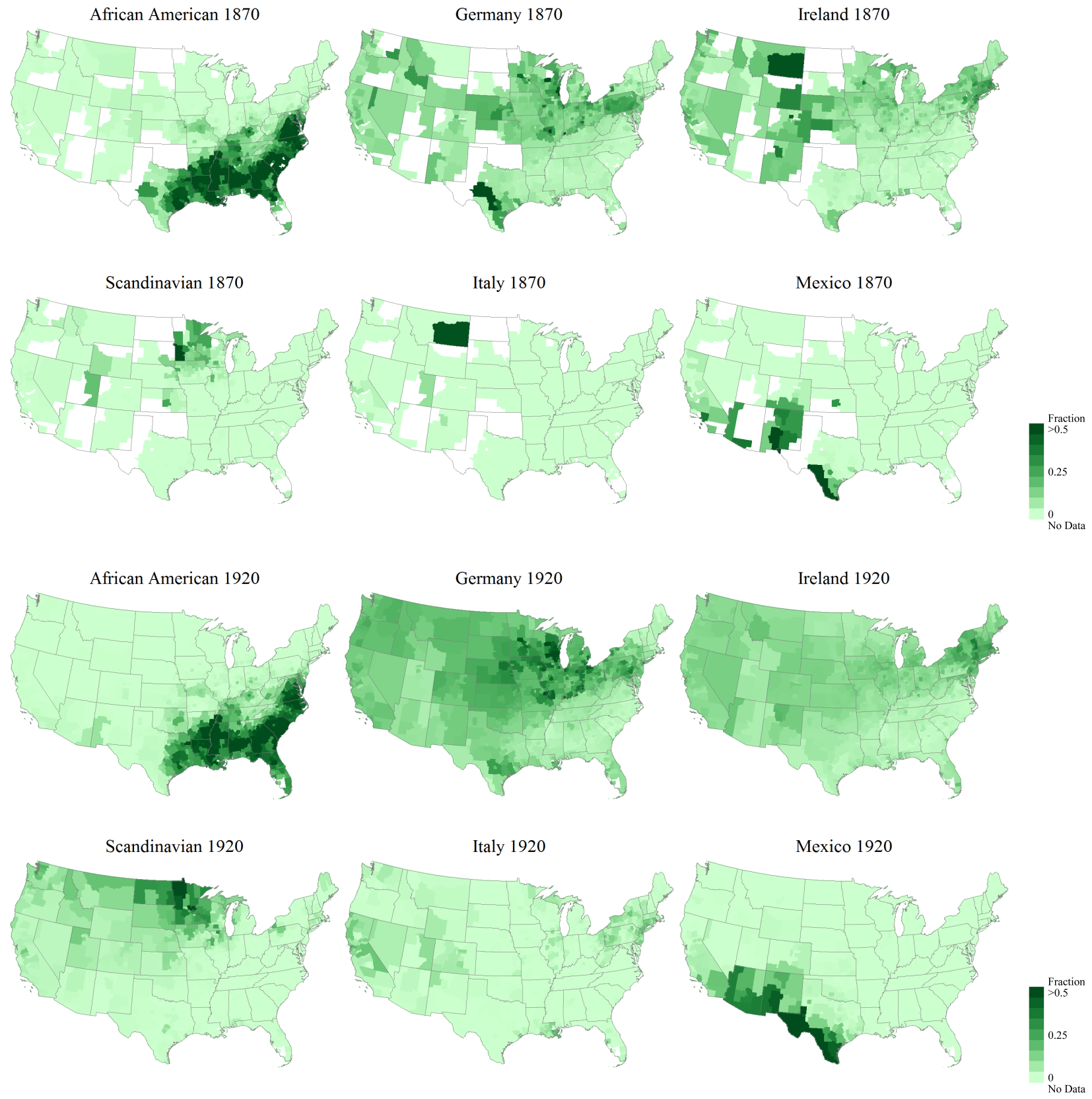

Notes: This figure shows the geographic distribution of select groups. Scandinavian is the combined Norway and Swedish ancestries. See Section 3 and the online appendix A for the ancestry construction. 
Figure 3: Select ancestries in the United States: 1970 and 2010
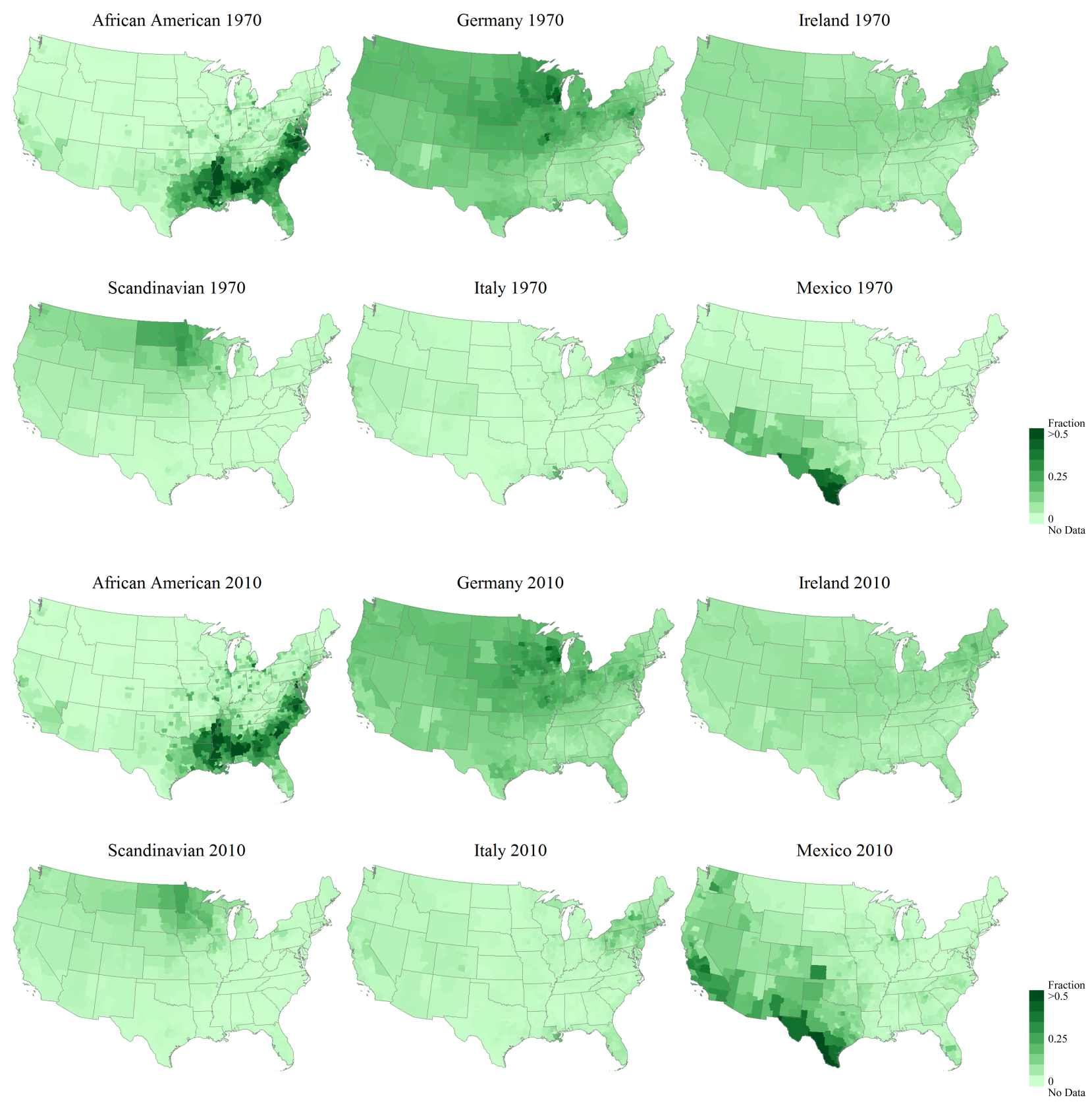

Notes: This figure shows the geographic distribution of select groups. Scandinavian is the combined Norway and Swedish ancestries. See Section 3 and the online appendix A for the ancestry construction. 
level GDP for services, construction, and mining. It is very important to include these components to capture both the geographical distribution and time profile of local GDP. The full details for how we construct our measure of county-level GDP and on the sources used are in the online appendix $\mathrm{B}$, but we describe our procedure briefly below. The basic idea is to combine the geographic distribution of employment in service industries, as reported by individuals in the census micro-samples, with historical wages to form an estimate of county services GDP. We then combine these estimates with estimates of manufacturing value added (equal to the value of output minus intermediate inputs) and agricultural value added (constructed using county agricultural output and a time varying national measure of the value-added-to-output ratio) to form a measure of county GDP.

To obtain county-specific measures of GDP for services, construction and mining, we use the employment and occupation information collected by the census micro-samples in each decade to construct employment by broad service category (trade, transportation and public utilities, finance, professional services, personal services, and government), construction and mining. Using census level employment and wage data in each county (or an estimate of the latter from other historical sources), one can then distribute national GDP in an industry according to the wage bill of each county relative to the national wage bill in that industry. Doing so is equivalent to multiplying county employment in an industry by a county-specific estimate of value added per worker in that industry, calculated by adjusting national valued added per worker in each industry by the local wage relative to the national wage. This adjustment allows the productivity of a worker in each sector (as proxied by the wage) to vary by location. ${ }^{11}$ We have the full wage bill for the 1940 census, and we use the same allocation for the adjacent decades of 1950 and 1930, when there is much sparser wage information. For decades before 1930, we have information on wages within each sector only at the state level (or for the major city within a state). For these periods, we combine this historical information with the detailed wage distribution available for the full sample in 1940 to obtain a wage distribution that is specific to a given state and allows for differences

\footnotetext{
${ }^{11}$ We show in the online appendix B that this approach is exactly what one ought to do under the assumption of perfect competition in output and factor markets and a constant returns to scale Cobb Douglas production function. This result holds even if the output market is monopolistically competitive, provided the markup is common across the United States.
} 
between urban and rural areas.

The census reports personal income at the county level starting in 1950 and no longer reports manufacturing and agricultural output in the same way. Using the overlap in 1950 between our measure of nominal GDP by county and income in each county from the census, we construct a ratio of GDP to income at the county level. We use this county-level ratio to get an estimate of GDP from 1960 onward. Effectively, we use the growth rate of income at the county level to approximate the growth rate of county-level GDP. We then calculate GDP for the same county groups used in constructing the distribution of ancestries. We convert nominal GDP to real GDP using the price deflator from Sutch (2006). In our analysis, we generally allow for census division specific year effects that absorb any census division differences in the evolution of the GDP deflator. Then we divide real GDP by the number of workers in each county, calculated by summing all persons who indicate an occupation in the census micro-samples.

Ours is the first measure of GDP at the county level that goes beyond a combined measure of manufacturing value added and agricultural output. By aggregating at the national level and at the state level, we can compare our measure to other calculations and thus provide some validation of our approach. Both the level and the growth rate at the national level closely track the GDP per capita from Sutch (2006) (see Figure A-2 in the online appendix). Our shares of GDP also closely match the shares calculated in the National Income and Product Accounts starting in 1929, although without the volatility of the Great Depression (see Figure A-3 in the the online appendix). When we aggregate at the state level, our state GDP per capita closely compares to estimates of state income per capita in 1880, 1900, 1920, and 1940, as shown in Figure A-4 in the the online appendix. Finally, our measure of GDP for county groups has a high cross sectional correlation (0.74) with Net Retail Sales in 1929 (see Figure A-5 in the online appendix). It goes without saying that our measure of county level GDP is imperfect. Yet it is a substantial improvement relative to what was available until now. Our regressions include time invariant county group fixed effects and census division-decade effects, so we control for missmeasurement that varies along these two dimensions. 


\section{Does ancestry matter and why?}

Combining our measure of the ancestry makeup of each county with our measure of county GDP, we ask whether ancestry matters for local economic development and, if so, which attributes brought by the immigrants from the country of origin play an important role.

What is crucial about our empirical approach is that, unlike most other studies of ethnicity or ancestry, we have at our disposal a panel of consistent data. The availability of panel data allows us to evaluate how important ancestry composition is for economic development, controlling for timeinvariant county characteristics, and examine how changes in the ancestry mix affect outcomes over time. Throughout the analysis, we limit the sample to 1870-2010 for two reasons: (1) the US Civil War (1861-1865) changed the economic landscape, making comparisons between the prewar and postwar periods difficult; and (2) the iterative construction means that from 1870 onward the ancestry shares are based on more decades of micro-sample information.

We start by asking whether groups have different effects using an unrestricted linear specification in which each ancestry is allowed to have its own effect on county GDP per worker (Section 5.1). We then examine which origin characteristics are correlated with these unrestricted ancestry effects (Section 5.2). To address additional questions of endogeneity and compare origin characteristics, we next turn to a more parsimonious approach that uses the ancestry-weighted average origin characteristic in a county (Section 5.3.1). We finally allow for higher order functions of the ancestry shares to matter to address the role of diversity (Section 5.4).

\subsection{Do ancestry groups have different economic effects?}

We begin by testing whether ancestries are different along any economically relevant dimension. Denote with $\pi_{c t}^{a}$ the share of the population of county $c$ at time $t$ whose ancestors came from a particular country-of-origin $a$ out of all possible ancestries $A$. Note that we examine how composition matters, not how the size of the population matters. We estimate variations of:

$$
y_{c t}=\theta_{c}+\theta_{d t}+\sum_{a=1}^{A} \alpha_{a} \pi_{c t}^{a}+\gamma X_{c t}+\epsilon_{c t},
$$


Table 1: County GDP per worker and individual ancestries

\begin{tabular}{lccccccc}
\hline \hline & \multicolumn{7}{c}{ Dependent variable: $\log$ (County group GDP per worker) } \\
\cline { 2 - 8 } & {$[1]$} & {$[2]$} & {$[3]$} & {$[4]$} & {$[5]$} & {$[6]$} & {$[7]$} \\
\cline { 2 - 8 } & & & & & & & \\
F(All ancestry =0) & 25.32 & 10.69 & 13.90 & 8.192 & 9.365 & 5.260 & 7.592 \\
$\quad$ p-value & 0 & 0 & 0 & 0 & $4.94 \mathrm{e}-08$ & 0 & 0 \\
F(non-AA anc. =0) & 16.05 & 8.833 & 8.624 & 6.291 & 3.444 & 4.026 & 3.317 \\
$\quad$ p-value & 0 & 0 & 0 & 0 & 0 & $3.57 \mathrm{e}-10$ & $1.41 \mathrm{e}-07$ \\
& & & & & & & \\
County group fixed effects & Yes & Yes & Yes & Yes & Yes & Yes & Yes \\
Year effects & Yes & & & & & & \\
Division X Year & & Yes & & Yes & Yes & Yes & Yes \\
State X Year & & & Yes & & & & \\
County group trends & & & & Yes & & Yes & \\
Two lags of county GDP & & & & & Yes & Yes & Yes \\
Education and pop. density & & & & & & & Yes \\
& & & & & & & \\
$R^{2}$ (within) & 0.938 & 0.947 & 0.962 & 0.963 & 0.970 & 0.977 & 0.969 \\
$R^{2}$ (between) & 0.378 & 0.424 & 0.485 & 0.0148 & 0.799 & 0.00332 & 0.804 \\
Observations & 18,447 & 18,447 & 18,447 & 18,447 & 16,144 & 16,144 & 15,916 \\
County groups & 1,149 & 1,149 & 1,149 & 1,149 & 1,146 & 1,146 & 1,146 \\
\hline
\end{tabular}

Notes: In this table we test whether ancestries have different effects on log county GDP per worker. Each column shows the results from a regression including the fraction of every ancestry except the English (the excluded group), allowing each ancestry to have its own effect on county GDP per worker. The F-tests test the joint hypothesis that the coefficients on all ancestries are jointly zero and so equal to the English. Education is the fraction literate before 1940 and average years of education after. The Non-AA F-test tests whether the coefficients for all ancestries, except African Americans and Native Americans, are jointly zero. All regressions contain county-group fixed effects and different versions of year effects. Standard errors are clustered at the county-group level.

where each ancestry can have its own unrestricted effect on log county GDP per worker $\left(y_{c t}\right)$ after controlling for county fixed effects $\left(\theta_{c}\right)$ and census division specific year effects $\left(\theta_{d t}\right)$, or variants thereof, and other possible controls $\left(X_{c t}\right)$. If ancestry composition does not matter, then all of the $\alpha_{a}$ coefficients will be equal (we use the English as the excluded reference ancestry).

Table 1 shows the results for many variations of equation (1), all of which strongly reject the hypothesis that ancestry composition does not matter. All estimates include county fixed effects, so the fixed characteristics of the place of settlement is controlled for. We include different combinations of year, year-division, or year-state effects in the first three columns, and then focus on census-division-year fixed effects. The remaining columns add county trends, two lags of county 
Figure 4: Individual ancestry coefficients

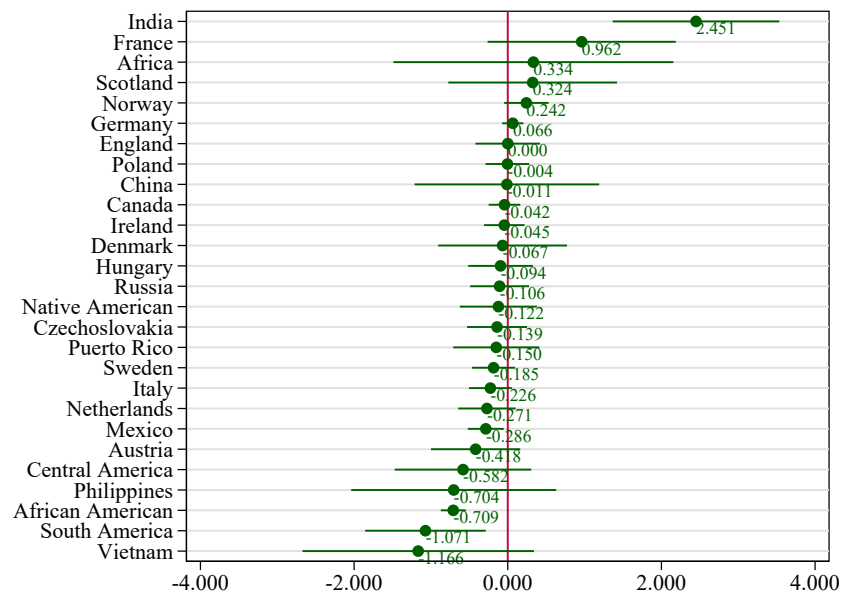

Notes: This figure shows effects on log county GDP per person for ancestry groups composing more than $0.5 \%$ of the population in 2010 (bars represent 95\% confidence intervals). The excluded group is England, which has an implied coefficient of 0 with a standard error equal to the one of the constant. The regression includes two lags of log county GDP and division by year fixed effects and is based on the results for column 5 of Table 1 .

GDP, and additional controls. The table shows the F-statistic for the joint test that all $\alpha_{a}$ are equal (each ancestry matters equally for GDP). ${ }^{12}$ To examine whether the results are purely driven by race, we also separately test the hypothesis that all ancestries other than African American and Native American have equal coefficients. Below each F-statistic we report its p-value. They are all zero to more decimal places than can fit in the table, strongly rejecting the hypothesis of equal effects.

The last column also includes other possible explanatory variables, such as population density and county-level education (measured first by literacy and then, after 1940, by average years of education). These variables represent potential channels through which ancestry may be related with economic development. The ancestry coefficients continue to be jointly significantly different from one another, even after including these controls, and so ancestry composition seems to matter beyond its relationship to education or urbanization.

In Figure 4 we report the actual ancestry coefficients (in deviation from the coefficient on

\footnotetext{
${ }^{12}$ Since individual effects for very small ancestry groups cannot be precisely estimated, we include only the ancestries that make up at least $0.5 \%$ of the population in 2010, which accounts for $93 \%$ of the population. In the estimation, we use people of English origin as the reference point and omit their fraction from the regression. The test, therefore, is whether the coefficients for the other ancestries are jointly zero.
} 
English ancestry) from column 5 of Table 1 . A coefficient of 0.24 for Norway means that replacing one percentage point of residents with English ancestry with 1 percentage point of those with Norwegian ancestry increases GDP per person by 0.24 percent within 10 years and approximately double that over the long term (the sum of the two lagged GDP coefficients is approximately 0.5). 13 These results raise the obvious question of what can explain such differences, which we turn to next. Yet these results should be treated with some caution as they do not consider the importance of diversity which we address later in the paper (see Section 5.4).

\subsection{What origin characteristics explain why ancestry groups have different effects?}

In this section, we examine which country of origin characteristics help explain why ancestry groups have different economic effects. We first introduce our origin variables. We then examine whether the ancestry effects are correlated with origin characteristics.

The main limiting factor in the analysis of origin attributes is the availability of information for a broad range of countries over long time periods. Unlike our data on ancestry and county GDP, which we have carefully constructed based on micro data to be as consistent as possible across time and space, the cross-country data is not always available or reliable, particularly in the distant past. The full details of the construction of and sources for the origin variables are in the online appendix D. ${ }^{14}$

To reflect the changing nature of what immigrants could bring with them, when the characteristics of the origin country are time varying, we weight them by the time of arrival of immigrant groups (see the online appendix $\mathrm{C}$ for our creation of the conditional arrival density for all groups). In addition, we measure most origin variables as their difference from the United States at arrival. As time goes by, differences at arrival are likely to diminish, and so we allow these differences to depreciate the longer an immigrant group has been in the US. Formally, given a country-of-

\footnotetext{
${ }^{13}$ In the online the online appendix, see Figure A-5, we report a similar figure obtained by combining ancestries from individual countries in larger groupings (for instance: Scandinavia, instead of individual Scandinavian countries). The results are similar but not as sharp, suggesting that there are important distinctions even between similar countries.

${ }^{14} \mathrm{We}$ only show results for origin variables that cover over $99 \%$ of the population in every county. Summary statistics for these variables appear in the online appendix Table A-2.
} 
origin measure $\hat{\mathrm{z}}_{\tau}^{a}$ for ancestry $a$ at the time $\tau$ of arrival and $\hat{z}_{\tau}^{U S}$ measure in the US, we form the arrival-weighted origin attribute $Z_{t}^{a}$ at time t:

$$
\mathrm{Z}_{t}^{a}=\sum_{\tau=0}^{t}\left(\hat{z}_{\tau}^{a}-\hat{z}_{\tau}^{U S}\right)(1-\delta)^{t-\tau} F_{t}^{a}(\tau)
$$

where $F_{t}^{a}(\tau)$ is the arrival density of group $a$ up to time $\tau$, which is 0 for $\tau>t$, and $\delta$ is the rate of depreciation of the importance of the origin.

As a summary variable for positive economic attributes, we form the Arrival-Weighted Origin GDP as the difference in log GDP per person in the country of origin and the log GDP per person in the United States at the time of immigration, depreciated at $0.5 \%$ per year, which implies that $40 \%$ of the difference between the origin country and the US disappears in 100 years. The particular rate of depreciation does not affect our results. Origin GDP is a useful summary variable, since it captures whether an ancestry has been exposed to the mix of characteristics that led to economic development in the ancestral homeland and thus helps understand whether ancestry groups carry a portion of what matters for economic success with them.

Following Tabellini (2010), we also use the World Values Survey (WVS) to construct a composite measure of cultural values that enhance productive social interactions by taking the first principal component of these values at the individual level from the WVS. ${ }^{15}$ In order to obtain a time-varying measure of culture, we separate the individual WVS answers by birth cohort (born before 1925, 1925-1949, 1950-1974, after 1975). This procedure allows us to capture, albeit imperfectly, the changing cultural values inherited from the country of origin by different waves of immigrants. We then take differences from the United States depreciated at $0.5 \%$ per year to form the arrival-weighted Principal Component of Culture using equation (2). We obtain similar results using arrival-weighted Trust constructed in the same way.

For institutions, we use the state history in 1500 from Borcan, Olsson, and Putterman (2018)

\footnotetext{
${ }^{15}$ Tabellini (2010) focuses on answers from the WVS that measure: (i) generalized trust; (ii) the respect of others as a desirable characteristic children should have; (ii) obedience as a desirable children's characteristic; (iv) feeling of control of one's own fortune. The basic idea is that trust, respect, and control are cultural traits that enhance productive social interaction, while obedience is not a useful trait in a society that values independence.
} 
(updating Bockstette, Chanda, and Putterman (2002)) that reflects for how long before 1500 a particular area had a centralized government above the local level and the extent that government was locally based (State History). Because State History is fixed at a point in time, it does not vary by time of arrival. Some modern states, such as Canada, are largely composed of migrants, so we adjust State History to reflect the state history experience of the population living there using the migration matrix of Putterman and Weil (2010). Other than Canada, few large in-migration countries also had substantial out-migrations to the United States, so this adjustment does not affect our results. We also measure the constraints on the executive power in the country of origin at the time of arrival of various immigrant waves (Executive Constraints at arrival). Finally, we construct Migrant Education at arrival by using literacy and years of education (after 1930) of immigrants from the census.

Figure 5 shows how a selection of arrival-weighted origin variables in 2010 relates to the individual ancestry effects we estimate in Table 1 column 5. We show 2010 arrival-weighted variables to capture the full experience of each immigrant group.

Origin variables associated with home-country economic development are positively associated with the estimated ancestry effects. Ancestry groups from countries that are richer, have longer state history, have more constraints on executive power, or that arrived with more education tend to have a large effect in their new homes. Groups from countries with a greater culture of cooperation (Principal Component of Culture) or more generalized trust (Trust) also have larger effects. We show the correlation with several other variables in the online appendix Figure A-7.

The ancestry coefficients in Figure 5 capture the many different effects that groups have. These effects may arise from many factors, including: their cultural endowments, the institutional experience and human capital they may have brought with them, their interaction with other groups, as well as the discrimination and oppression they may have faced. Yet the strong correlation between the individual ancestry coefficients and different origin attributes suggests that the endowments they brought matter. We first turn to capturing these relationships parsimoniously then consider the role of group diversity. 
Figure 5: Ancestry and endowments from the country of origin
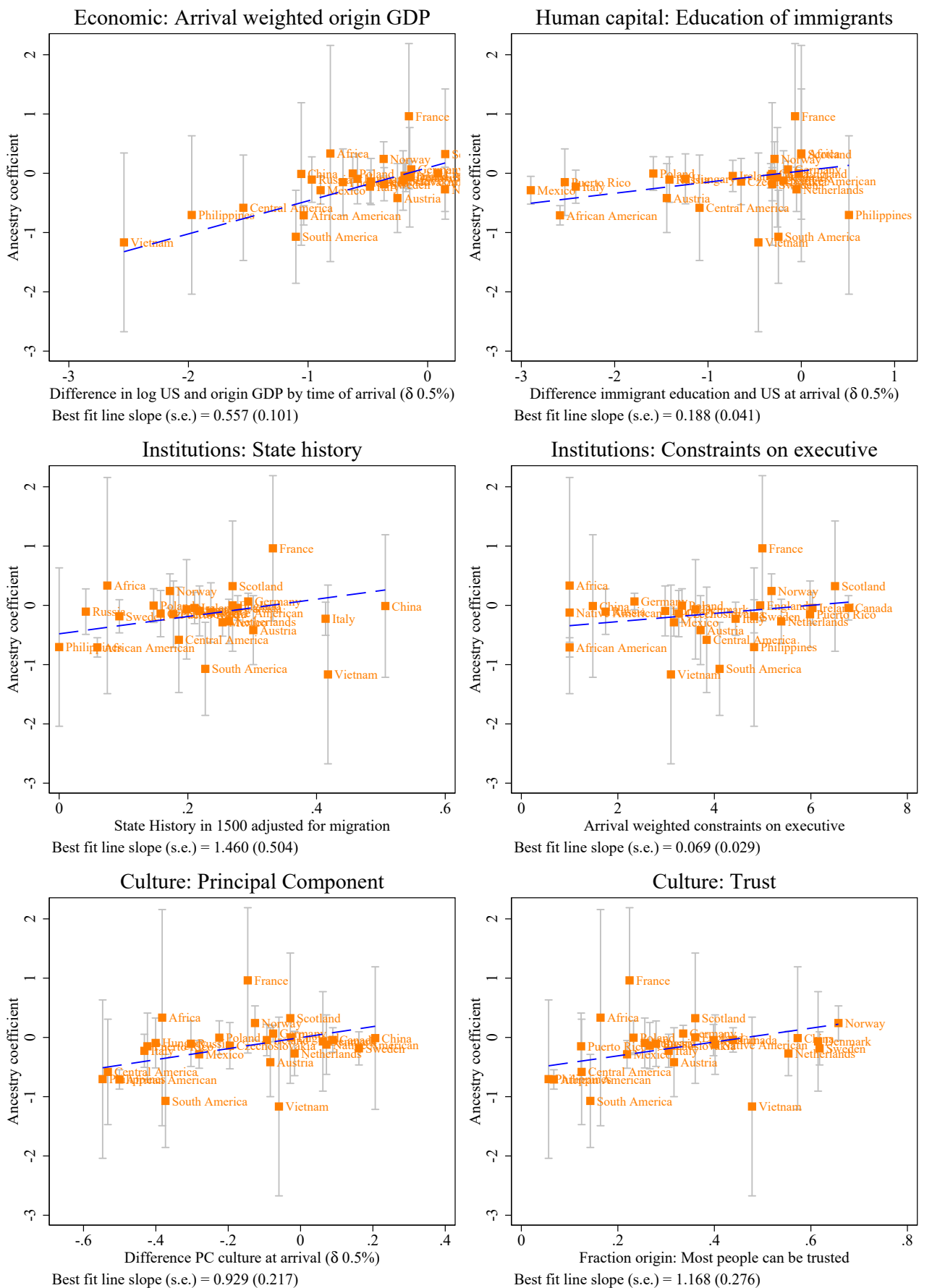

Notes: This figure shows the relationship between variables in the country of origin and the coefficients estimated for large ancestry groups in the log county GDP per worker equation (1), including county group fixed effects, census division by year effects, and two lags of log county GDP per worker (column 5 in Table 1). Time-varying origin country measures are constructed as the immigrant arrival-weighted density of that country as in equation (2) (see the online appendix $\mathrm{C}$ for sources and calculation of arrival density and the online appendix $\mathrm{D}$ for the sources of the origin variables). 


\subsection{A parsimonious representation of origin characteristics}

In this section, we introduce a more parsimonious representation of the origin characteristics by constructing an ancestry-weighted average of origin endowments. We start by examining origin country GDP per person in Section 5.3.1, and then we turn to more specific origin characteristics in Section 5.3.3. We define the county average endowment as:

$$
z_{c t}=\sum_{a=1}^{A} \pi_{c t}^{a} \mathrm{Z}_{t}^{a}
$$

for arrival-weighted origin characteristic $Z_{t}^{a}$ defined as in equation (2) in the previous section. We can think of $z_{c t}$ as the average or predicted value, across origin countries $a$, of the endowment of a given characteristic, $Z_{t}^{a}$. We use the lowercase italics to help denote the endowment variable weighted by the ancestry share, and uppercase letters for the endowment characteristic itself. When the country of origin characteristic is time invariant, the county-level average endowment will change only because of changes in ancestry composition.

Our typical regression takes the general form:

$$
y_{c t}=\theta_{c}+\lambda_{d t}+\beta z_{c t}+\gamma X_{c t}+\epsilon_{c t}
$$

In some specifications $z_{c t}$ will be a vector of the ancestry-weighted values of the endowment of several characteristics and in most specifications $X_{c t}$ will include two lagged values of $y_{c t}$. Note that, implicitly, we are imposing the restriction that the ancestry coefficients in the unrestricted model of equation (1) are proportional to one or more elements of the immigrant endowment vector. The basic idea is that such endowments determine the effect of each ancestry group on local GDP per worker. The inclusion of lagged values of GDP per worker is meant to capture the fact that the impact of such endowments on local development is distributed over time. There are multiple reasons for this to be the case, such as the presence of autocorrelated shocks to technology or learning by doings effects. 
Table 2: County GDP per worker and country-of-origin GDP

\begin{tabular}{|c|c|c|c|c|c|c|c|c|}
\hline & \multicolumn{8}{|c|}{ Dependent variable: $\log ($ county GDP per worker) } \\
\hline & \multicolumn{2}{|c|}{ Static } & \multicolumn{6}{|c|}{ Dynamic } \\
\hline & $\mathrm{FE}$ & OLS & $\mathrm{FE}$ & $\begin{array}{l}\text { FE with } \\
\text { Race }\end{array}$ & $\begin{array}{l}\text { FE with } \\
\text { Neighbor }\end{array}$ & $\begin{array}{c}\text { IV1 } \\
\text { FE }\end{array}$ & $\begin{array}{c}\text { IV2 } \\
\text { FE }\end{array}$ & $\begin{array}{c}\text { IV3 } \\
\text { GMM }\end{array}$ \\
\hline & [1] & {$[2]$} & [3] & [4] & [5] & [6] & [7] & [8] \\
\hline $\begin{array}{l}\text { Origin GDP } \\
\quad(\text { ancestry weighted) }\end{array}$ & $\begin{array}{l}0.310 * * * \\
(0.0431)\end{array}$ & $\begin{array}{c}-0.172 * * * \\
(0.0409)\end{array}$ & $\begin{array}{l}0.331 * * * \\
(0.0253)\end{array}$ & $\begin{array}{l}0.152 * * * \\
(0.0290)\end{array}$ & $\begin{array}{l}0.319 * * * \\
(0.0340)\end{array}$ & $\begin{array}{l}0.354 * * * \\
(0.0172)\end{array}$ & $\begin{array}{l}0.319 * * * \\
(0.0426)\end{array}$ & $\begin{array}{l}0.197 * * * \\
(0.0357)\end{array}$ \\
\hline $\begin{array}{l}\text { Decade lag } \\
\text { log county GDP }\end{array}$ & & & $\begin{array}{c}0.445 * * * \\
(0.0161)\end{array}$ & $\begin{array}{r}0.436 * * * \\
(0.0163)\end{array}$ & $\begin{array}{c}0.444 * * * \\
(0.0169)\end{array}$ & $\begin{array}{l}0.442 * * * \\
(0.00777)\end{array}$ & $\begin{array}{c}0.456 * * * \\
(0.0170)\end{array}$ & $\begin{array}{l}0.555^{* * * *} \\
(0.0181)\end{array}$ \\
\hline $\begin{array}{l}\text { Two decade lag } \\
\text { log county GDP }\end{array}$ & & & $\begin{array}{l}0.0286^{*} \\
(0.0167)\end{array}$ & $\begin{array}{l}0.0270^{*} \\
(0.0160)\end{array}$ & $\begin{array}{l}0.0281^{*} \\
(0.0166)\end{array}$ & $\begin{array}{r}0.0307 * * * \\
(0.00687)\end{array}$ & $\begin{array}{c}0.0513 * * * \\
(0.0125)\end{array}$ & $\begin{array}{c}0.0993 * * * \\
(0.0185)\end{array}$ \\
\hline Division X Year FE & Yes & Yes & Yes & Yes & Yes & Yes & Yes & Yes \\
\hline County group FE & Yes & & Yes & Yes & Yes & Yes & Yes & Yes \\
\hline Long-run effect & 0.310 & -0.172 & 0.629 & 0.283 & 0.604 & 0.671 & 0.647 & 0.570 \\
\hline Observations & 16,713 & 16,713 & 14,415 & 14,415 & 14,415 & 14,415 & 13,232 & 14,415 \\
\hline County groups & 1149 & & 1146 & 1146 & 1146 & 1146 & 1023 & 1146 \\
\hline$R^{2}$ (within) & 0.950 & 0.887 & 0.968 & 0.968 & 0.968 & & & \\
\hline$R^{2}$ (between) & 0.113 & & 0.472 & 0.486 & 0.446 & & & \\
\hline $\mathrm{AB}$ test serial corr. & $6.01 \mathrm{e}-07$ & & 0.309 & 0.269 & & 0.370 & 0.727 & 0.203 \\
\hline First Stage & & & & & & Dep & var: Origin & $G D P$ \\
\hline proj. Origin GDP & & & & & & $\begin{array}{l}0.849 * * * \\
(0.00410)\end{array}$ & $\begin{array}{l}1.217 * * * \\
(0.0129)\end{array}$ & \\
\hline First stage $R^{2}$ & & & & & & 0.887 & 0.735 & \\
\hline Kleibergen-Paap F & & & & & & 5660 & 1441 & \\
\hline
\end{tabular}

Notes: In this table we examine whether Origin GDP (the ancestry-weighted log difference between origin GDP per person and US GDP per person at the time of arrival, depreciated at a rate of $0.5 \%$ per year) matters for log county GDP per worker in variations of equation (4). In the dynamic specification columns, the long-run effect is the the coefficient on Origin GDP divided by $\left(1-\rho_{1}-\rho_{2}\right)$, with the $\rho$ 's denoting the coefficients on the lag dependent variable. Column 4 includes the fraction African American and Native American separately (the coefficients are not reported). Column 5 includes the average of the county's neighbors' Origin GDP and county GDP in the previous decade. Column 6 instruments for Origin GDP using the Origin GDP constructed using ancestry in the previous decade (Approach 1; see Section 5.3.2). Column 7 instruments using the interaction between the transportation network and total ancestry migration (Approach 2). Distance to transportation is included in both first and second stages, in addition to lags of log county GDP per worker. Column 8 contains the GMM esimates (Approach 3), using orthogonal deviations and lags 2 through 4 as instruments. The AB test is the p-value for the Arellano and Bond (1991) test for second order serial correlation of the errors in difference. All regressions include census division by year fixed effects and standard errors clustered at the county group level. $* * * \mathrm{p}<0.01, * * \mathrm{p}<0.05, * \mathrm{p}<0.1$. 


\subsubsection{Origin development and county development}

Table 2 shows a series of estimates of equation (4) for ancestry-weighted Origin GDP per capita used as a summary measure of the endowment brought by immigrants and partly passed down to their descendants. We address questions of reverse causality due to endogenous migration following local shocks in the next section. All of the estimates include census-division-specific year effects. Because much of the variation in the effect of ancestry is likely to be felt across regions, including census-division-year effects removes some variation but ensures that the estimates are not driven purely by differential regional trends. ${ }^{16}$

When we use fixed effects to control for all of the time invariant aspects that may affect economic development in column 1 of Table 2, the coefficient on Origin GDP is positive and significant at the $1 \%$ level. The estimates imply that when the people who make up a county come from places that are $1 \%$ richer, county GDP per worker is $0.3 \%$ higher. While the association of Origin GDP with local GDP is positive and significant in column 1 with fixed effects, the association is negative and significant in column 2 without county fixed effects. The negative coefficient illustrates just how important having a panel is. Cross-sectional regressions, even ones controlling for regional differences, may deliver severely biased results. The negative coefficient is likely particular to the settlement of the United States, but the possibility of bias in a cross-section is a more general problem. ${ }^{17}$ Allowing for county effects also controls for an arbitrarily complicated spatial correlation.

Because the effect of changes in ancestry may take some time to be fully felt, in columns 3 through 5 of Table 2 we show a dynamic specification including two lags of county GDP per

\footnotetext{
${ }^{16} \mathrm{We}$ use census divisions instead of states, since states vary tremendously in size and census divisions are much more similar in terms of geographic and population size. States such as Rhode Island also have very few county groups, and so including a fixed effect for them removes almost all variation.

${ }^{17}$ The primary driving force behind this correlation is the historical legacy of settlement, starting with the English. While the English are a large portion of the population in much of the United States, they are disproportionately present in rural areas in the poor South and Appalachian states, which received little immigration after their first settlement. Later immigrants, such as the Italians or Irish, while poor when they arrived, went to cities and prosperous areas, especially in the Northeast. Finally, the Great Migration of African Americans shifted them from the poor rural South to growing urban areas.
} 
worker. ${ }^{18}$ There is evidence of severe serial correlation in column 1, according to the Arellano and Bond (1991) test. ${ }^{19}$ By including previous periods of the dependent variable county GDP per worker, we can remove the serial correlation as well as examine how the impact of ancestry evolves. The dynamic model suggests that the effects of a permanent change in the ancestry mix are felt about half within a decade, and half over the long term. ${ }^{20}$ The long-term effect is now quite large: if the people who make up a county come from places that are $1 \%$ richer, county GDP per worker is $0.6 \%$ higher.

Columns 4 and 5 examine possible variations by including race and allowing for neighbors to have an effect. We permit African Americans and Native Americans to have an unrestricted coefficient, because the information on the "original" level of GDP for African Americans and Native Americans is necessarily speculative and does not capture fully the legacy of slavery, oppression and discrimination for these groups. ${ }^{21}$ The coefficient on Origin GDP in column 4 captures, therefore, the endowment effect for groups other than African American or Native American. It remains very significant, although it is now smaller, suggesting that while race is an important part of ancestry, it is not the only part. In column 5, we include a one decade-lag of a county group's neighbors' average Origin GDP and county GDP. ${ }^{22}$ Because the fixed effects already allow for an arbitrary fixed spatial relationship, the standard issue of spatial correlation is small, and adding a spatial lag

\footnotetext{
${ }^{18}$ In the the online appendix we show that Nickell (1981) bias due to T being relatively short (around 14) does not affect these results. Note, moreover, that $t$ indexes decades.

${ }^{19}$ The test is for second-order serial correlation in the first difference of the errors, which provides information on first-order serial correlation of the errors in level.

${ }^{20}$ The coefficient of first lag is highly significant and sizable (.44), while the one for the second lag is smaller and significant at the $10 \%$ level. While the second order lag is only sometimes significant across the different specifications, excluding it often causes the Arellano and Bond (1991) test of serial correlation to fail to reject the hypothesis of no serial correlation of $\epsilon_{c t}$, and so we standardize on including two lags. The long-run multiplier, in a single equation context, is $\beta /\left(1-\rho_{1}-\rho_{2}\right)$, where $\beta$ is the coefficient of each ancestry-weighted endowment variable, and $\rho_{1}$ and $\rho_{2}$ are the coefficients on the lags of county GDP.

${ }^{21}$ Where available, we assign the values of Ghana, a West African country that was at the heart of the slave trade, to African Americans, and typically use overall US values for Native Americans. The results are nearly identical if we also allow those with African ancestries from the West Indies to have their own independent effect.

${ }^{22} \mathrm{We}$ lag the variables one decade to avoid the obvious identification problem of reflection: if neighboring countys affect each other simultaneously, then it requires an identification assumption to separate a county effect from a neighbor effect. A lag implicitly assumes that it takes a decade for a shock in one county to affect its neighbors, which seems the most sensible assumption. Note that fixed effects are far more flexible for spatial correlations than the standard functional form assumptions of spatial lags. The only concern is whether shocks may propagate spatially, which does not seem to be the case.
} 
variable has no additional effect.

In the online appendix Table A-6, we examine whether these results are robust to some other specifications. We first show that our results do not change when we allow the difference on arrival to depreciate faster or slower. When we allow the effect of ancestry to differ between metropolitan and non-metropolitan areas, there is some statistically weak evidence that the effect is slightly smaller in a metropolitan county. When we allow the coefficients to differ before and after 1940, the coefficient of Origin GDP does not differ economically and statistically between the two subperiods. Clustering errors at the state-year level does not affect the significance of our results. The overall conclusion is that the coefficients appear to be largely stable over time and cross-sectionally.

Finally, a possible concern is that immigrants may be a selected group with specific traits (see, for example, Abramitzky, Boustan, and Eriksson (2012)). To the extent that such selection is true of all origins, it does not affect the validity of our results in capturing the effect of origin country characteristics. Yet immigrants from different countries or times may select themselves differently. To examine how important this concern might be, we include the value of the ancestry-weighted Gini coefficients in the origin country at the time of arrival (weighted by arrival density) in our standard regressions. The idea, motivated by Borjas (1987), is that selection issues may be more important for origin countries that have a more unequal income distribution. Including the Origin Gini leaves the coefficient on Origin GDP largely unchanged (see column 6 in appendix Table A-6), so differential selection does not seem to affect our results.

\subsubsection{Endogenous Migration and Reverse Causality}

The inclusion of county-specific effects in equation 4 eliminates endogeneity that may arise if certain ancestries are attracted to places with particular time-invariant characteristics omitted from the specification. However, it is also possible that a shock to county GDP (not controlled for by our census regions time effects) may disproportionately attract migrants of a specific type, creating a form of reverse causality. For example, it could be that a booming county disproportionately attracts immigrants from poorer countries, since, if they are poorer on average, they may be the ones 
with greater incentives to move, in which case the effect of ancestry may be under-estimated. A counterargument is that the most mobile people may be those from richer countries as they may be the ones with characteristics that allow them to take advantage of new opportunities, and so the effect of ancestry may be over-estimated. We introduce three approaches with different identification assumptions and show that this form of endogeneity does not affect our main conclusions.

Approach 1: Immigrants tend to go where there are already immigrants from their country (Bartel, 1989). Growth of native groups similarly occurs in places where there are already populations of that ancestry. We build on these observations to create an instrument for ancestry based on the past stock of ancestry, in the spirit of Card (2001) and others in the immigration literature, such as Peri (2012).

We form our instrument starting with the population $P_{c, t-1}^{a}$ of ancestry $a$ in county $c$ at time $t-1$. We predict the $c$ 's population at time $t$ as: $\tilde{P}_{c, t}^{a}=P_{c, t-1}^{a}\left(1+g_{(-s(c)) t}^{a}\right)$, where $g_{(-s(c)) t}^{a}$ is the growth rate of ancestry $a$ from $t-1$ to $t$ in all states except the state containing county $c$. Summing over all the ancestries gives the predicted total population in each county, $\tilde{P}_{c, t}$. The predicted share of ancestry $a$ 's population in each county is then $\tilde{\pi}_{c, t}^{a}=\tilde{P}_{c, t}^{a} / \tilde{P}_{c, t}$. We then form predicted ancestryweighted variables $\tilde{z}_{c t}$ using equation (3) using $\tilde{\pi}_{c, t}^{a}$ instead of $\pi_{c, t}^{a}$ and use $\tilde{z}_{c t}$ as an instrument for $\mathrm{z}_{c t}$.

To meet the exclusion restriction, the instrument must be uncorrelated with the error term at $t$ in equation (4). By construction, $\tilde{z}_{c t}$ does not use any county specific information from decade $t$ and, by using the growth rate excluding a county's state, does not use any information from surrounding counties either. However, $P_{c, t-1}^{a}$ could potentially be correlated with the error term in $t-1, \epsilon_{c t-1}$. This would invalidate the instrument if there is serial correlation $\left(\operatorname{Cov}\left(\epsilon_{c t}, \epsilon_{c t-1}\right) \neq 0\right)$. We will show that when we include two lags of the dependent variable, there is no evidence of serial correlation in the errors using the Arellano and Bond (1991) test, so it is legitimate to use $\tilde{z}_{c t}$ as an instrument.

Approach 2: In this approach, we do not use county level information on the distribution of ancestries in the previous decade. Instead, we build on Sequeira, Nunn, and Qian (2019), who use 
the fact that, because immigrant groups arrived at different times, groups were exposed to different transportation networks and different geographic opportunities, so tended to go to different places. When a group is migrating, however, is unlikely to be related to county specific shocks in the destination county. Therefore, using the interaction between the transportation network and migration time as an instrument for county ancestry captures variation in ancestry not coming from ancestry characteristics.

More specifically, to form the instrument, we construct a population prediction that allocates the moving population based on where individuals would decide to go based on the the railway network and, later, the highway system at the time of migration. Formally, let $I_{t}^{a}$ be the population of international immigrants from $a$ between $t-1$ to $t$ and $M_{t}^{a}$ be the population of ancestry $a$ internal migrants who leave their state of residence between $t-1$ and $t$. Then the national change in the population of non-movers is $\Delta P_{t}^{N M}=P_{t}-P_{t-1}-\sum_{a}\left(I_{t}^{a}+M_{t}^{a}\right)$. We form our instrument iteratively using the predicted population from the previous decade $\hat{P}_{c t-1}^{a}$ (starting with $\left.P_{c 1870}^{a} \equiv \hat{P}_{c 1870}^{a}\right)$. In each decade we form the prediction:

$$
\hat{P}_{c t}^{a}=\hat{P}_{c t-1}^{a}\left(1+\frac{\Delta P_{t}^{N M}}{P_{t-1}}\right)+\frac{d_{c t}}{\sum_{c} d_{c t}}\left(I_{t}^{a}+M_{t}^{a}\right),
$$

where $d_{c t}$ is a measure of closeness to the transportation network. We measure $d_{c t}$ as a combination of: (1) an indicator of being part of the railroad or interstate network to capture that ease of access may be an important part of where migrants locate; and (2) an index of how close to newly constructed railroad or interstate segments to allow for the fact that newly accessible areas may be more (or less) desirable. We find the weights to combine these measures together into a single index using a "zero stage" regression. the online appendix, Section E contains the details. Our source for the time-varying railroad network is Sequeira, Nunn, and Qian (2019) and the interstate network is Baum-Snow (2007).

The first term in equation (5) is the national growth in the non-moving population which captures the overall growth in population not associated with migration. The second term allocates the entire moving population of $a\left(I_{t}^{a}+M_{t}^{a}\right)$ based on county $c$ 's relative access to transportation. 
Using the relative access to transportation means that sum over all counties and ancestries gives the total population in a given year: $\sum_{c, a} \hat{P}_{c t}^{a}=P_{t}$, so that we are allocating every mover to some county. Then the transportation-predicted ancestry share is:

$$
\hat{\pi}_{c t}^{a}=\frac{\hat{P}_{c t}^{a}}{\sum_{a} \hat{P}_{c t}^{a}} .
$$

We use the transportation-predicted ancestry share to form $\hat{z}_{c t}=\sum_{a} \hat{\pi}_{c t}^{a} Z_{t}^{a}$ and use $\hat{z}_{c t}$ as an instrument for $z_{c t}$. Note that, by construction, the only county specific component of $\hat{\pi}_{c t}^{a}$ is from the relative access to transportation and the only ancestry specific component is from national time-varying ancestry migration.

A potential concern is that the transportation network is likely related to county shocks, for example, if a new railroad line is built to access a booming county. This might invalidate using $\hat{z}_{c t}$ as an instrument for $z_{c t}$ if, for example, the same local boom that attracts the railway also attracts ancestries with particular characteristics. Therefore, we control for $d_{c t}$ directly in both first and second stage regressions, along with our standard fixed effects, region-year effects, and once and twice lagged county GDP. We have also experimented with including the interaction between $d_{c t}$ and $y_{c t-1}$ to both equations in order to allow the transportation network to enter even more flexibly, but have not found that doing so affects the results (see the online appendix E and Table A-4).

In addition, it is possible that shocks to a county may be so large that they affect national migration and immigration flows. This issue is only a concern for our cross-ancestry results if the county-specific shock affects national flows differently across ancestries. In the online appendix Table A-4, we show results constructing $\hat{\pi}_{c t}^{a}$ using $I_{t}^{a}$ and $M_{t}^{a}$ that exclude the migration flows that go to the county's state. Doing so removes any county-specific impact on the flow, as well as shocks that affect a set of counties within the state or even the state as a whole. The results are nearly identical.

After controlling for all these factors, using the interaction between the total number of people on the move of each ancestry at a given time and the transportation network to construct ancestry shares isolates county-ancestry variation that is unlikely to be related to group characteristics that 
may lead a particular ancestry to move disproportionately to a given county in response to shocks to local development opportunities.

Approach 3: Both approach 1 and 2 instrument the weighted endowments after applying the within transformation. A well developed literature starting with Holtz-Eakin, Newey, and Rosen (1988) and Arellano and Bond (1991) provides GMM estimates of dynamic panels containing endogenous variables using alternative transformations, such as first differencing or deviations from the forward mean (orthogonal deviations). Similar to Approach 1, appropriately lagged values of endogenous variables are used as instruments, so the GMM approach also requires the error term not to be autocorrelated, although there could be low order moving average components. This approach also deals with the potential for Nickell (1981) bias, which can arise when including fixed effects and lagged dependent variable (or other predetermined and endogenous variables) when $\mathrm{T}$ is short. Moreover, this methodology can be used to estimate the reduced form of a vector auto-regression to allow ancestry and county GDP to co-evolve.

At their core, both the GMM approach 3 and approach 1 (past shares augmented by the national growth rate of all immigrants) rely on the past distribution of ancestries. As the ancestry distribution in one decade is highly predictive of the distribution in the next, these instruments have highly predictive first stages. Of course, the validity of these instruments relies on the past shares being uncorrelated with current shocks. One therefore needs to be careful to use this approach only in dynamic models where we can test for-and reject — the presence of serial correlation in the error term. The instrument based on the interaction between immigrant arrival time and the railway and highway network is less dependent on the ancestry shares in the recent past and only uses the shares in 1870 , but also in this case it makes sense to use dynamic models as the effect of ancestry is likely to be felt over time. It is comforting, as we show next,that the basic conclusions remain very similar across the three approaches.

IV and GMM Results: The results for all three instrumenting strategies are reported in Table 2. Both Approach 1 and 2 yield results that are very similar qualitatively and quantitatively to the result when we do not instrument, and so we can conclude that our results are not driven by 
short-term endogenous migration. The first stage regression reported at the bottom of the Table 2 suggests that both instruments are highly correlated with Origin GDP (the p value of the t statistic is 0 to at least five decimal places and the same is true for the Kleibergen-Paap F statistics). In all cases, the Arellano and Bond (1991) test rejects the presence of serial correlation in the residuals. Note that when using Approach 2 we also include our index of closeness to the transportation network in the first and second stage, besides the other usual regressors. Doing so removes the concern that transportation-predicted ancestry is just picking up the importance of transportation, rather than ancestry.

The conclusions obtained when using GMM for dynamic panels are also similar and lead to the same general conclusions. ${ }^{23}$ In column 8 , the sum of the coefficients of the lagged dependent variables is somewhat larger as we would expect in the presence of a Nickell (1981) bias, but the difference is relatively small. The impact effect of ancestry is smaller, but it remains highly significant and the long run effect is similar. Again, there is no evidence of serial correlation in the residuals according to the Arellano and Bond test. Moreover the test of over-identifying restrictions (Hansen test) does not suggest model mis-specification. In the online appendix E and Table A-5, we show additional variations using GMM.

We can go further and estimate the reduced form of a bivariate vector autoregression in which we allow ancestry to affect county GDP and county GDP to affect Origin GDP. The results are reported in Figure 6 under two opposite identification assumptions: either county-level GDP per worker affects Origin GDP with a lag, or the converse is true (see the online appendix Table A5for the coefficients). Either assumption generates a recursive system and allows one to recover the impulse response function to structural shocks. Innovations in Origin GDP have a significant and sizable initial effect on county GDP, which grows until about the third decade. County GDP has an inconsequentially small effect on Origin GDP, suggesting that differential ancestry migration because of shocks is not a concern, as our instrumental results suggested. These results suggest some of the ancestry effect must be relatively immediate, but more than half of the effect shows up

\footnotetext{
${ }^{23}$ We have used the Roodman (2009) Stata routine xtabond2 for single equation GMM estimation and the Abrigo and Love (2015) routine for VAR GMM estimation.
} 
Figure 6: Impulse responses from VAR for log county GDP per worker and ancestry-weighted Origin GDP

Identification assumption: No immediate effect of GDP on Origin GDP
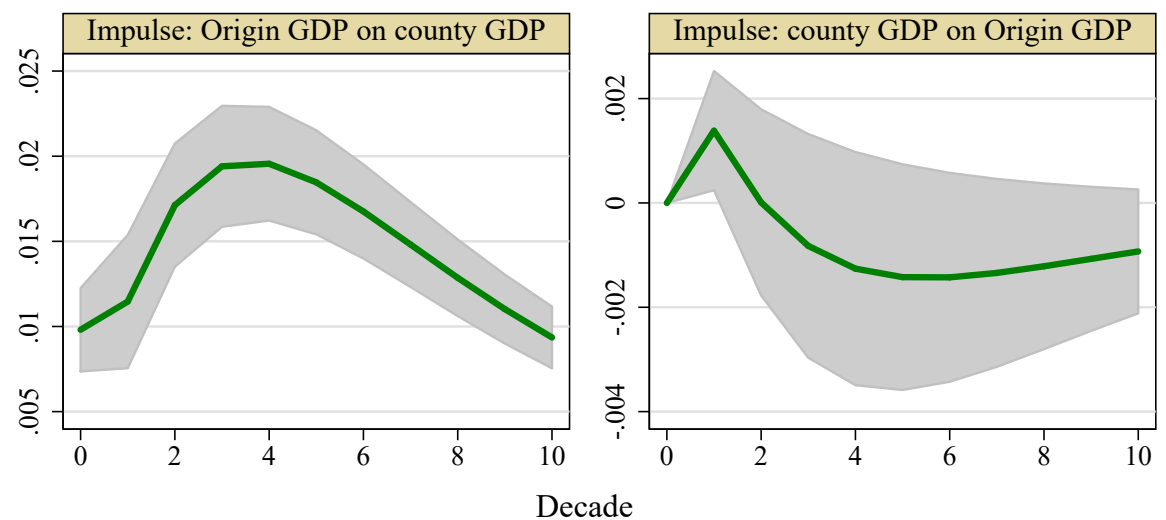

Identification assumption: No immediate effect of Origin GDP on GDP
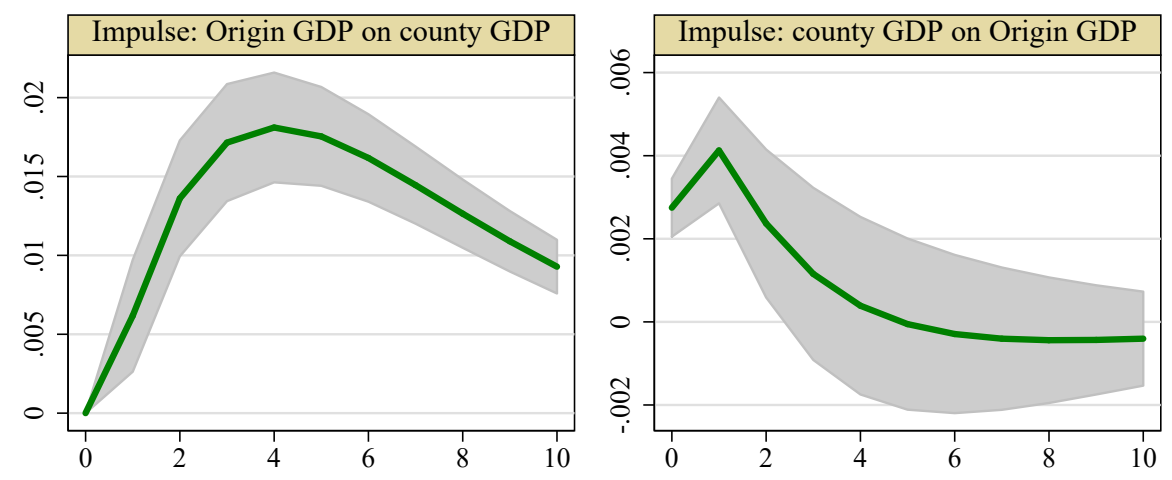

Decade

Notes: This figure shows impulse responses of a panel vector autoregression examining the co-evolution of ancestry weighted Origin GDP and county GDP. See the online appendix E and Table A-5 for the VAR coefficients. The impulses are calculated using two different identification assumptions: (1) No immediate effect of shocks to $\log$ county GDP per worker on ancestry weighted Origin GDP, but shocks to Origin GDP can immediately affect county GDP, (2) No immediate effect of shocks to Origin GDP on log county GDP per worker, but county GDP shocks can immediately affect Origin GDP. The size of the impulse is the standard deviations of the residuals in each equation. Shaded areas are the $95 \%$ confidence intervals based on Monte Carlo simulation. 
only after several decades.

\subsubsection{Origin characteristics and county development}

Which specific attributes and characteristics brought from the origin country help explain the association between ancestry and development? Table 3 takes a selection of the endowment measures and examines which measures are significant by themselves and in combination with each other. Given the significance of lagged values of county GDP, we focus only on the dynamic specification and always include county fixed effects and census-division-year effects. Each of the culture, institution, and human-capital variables are significant when included one at the time in Table 3 (columns 1 through 6). When we include the ancestry-weighted measures of culture, institutions, and human capital together, the coefficients on Principal component of culture and State history in 1500 remain highly significant, while the Migrant education coefficient is not significant (column 7). This may be because public schooling reduces educational differences and schooling policies respond endogenously to immigration flows (Bandiera et al., 2019). When we include the fraction of African American and of Native Americans as additional controls the coefficient of the Principal component of culture is not significant, but the one for State History in 1500 remains significant, although its size its now smaller (column 8). The coefficients of Executive constraint at arrival and Political Participation have small and not significant coefficients when added to the specification with State history in 1500. These variables represent political institutions that may change more rapidly and with which immigrants may have more limited experience, and so it makes sense that they have little effect in the United States. The importance of early political centralization for development is consistent with the results obtained by Michalopoulos and Papaioannou (2013) and Gennaioli and Rainer (2007). ${ }^{24}$

These results suggest that multiple endowments play a role in development, although we should

\footnotetext{
${ }^{24} \mathrm{We}$ obtained very similar results using Trust instead of Principal Component of Culture, but we prefer the specification with Principal Component, as it is based on multiple complementary cultural traits that denote the ability to interact with others. Thrift did not play a significant role when included.
} 
Table 3: County GDP per worker and ancestry-weighted origin characteristics

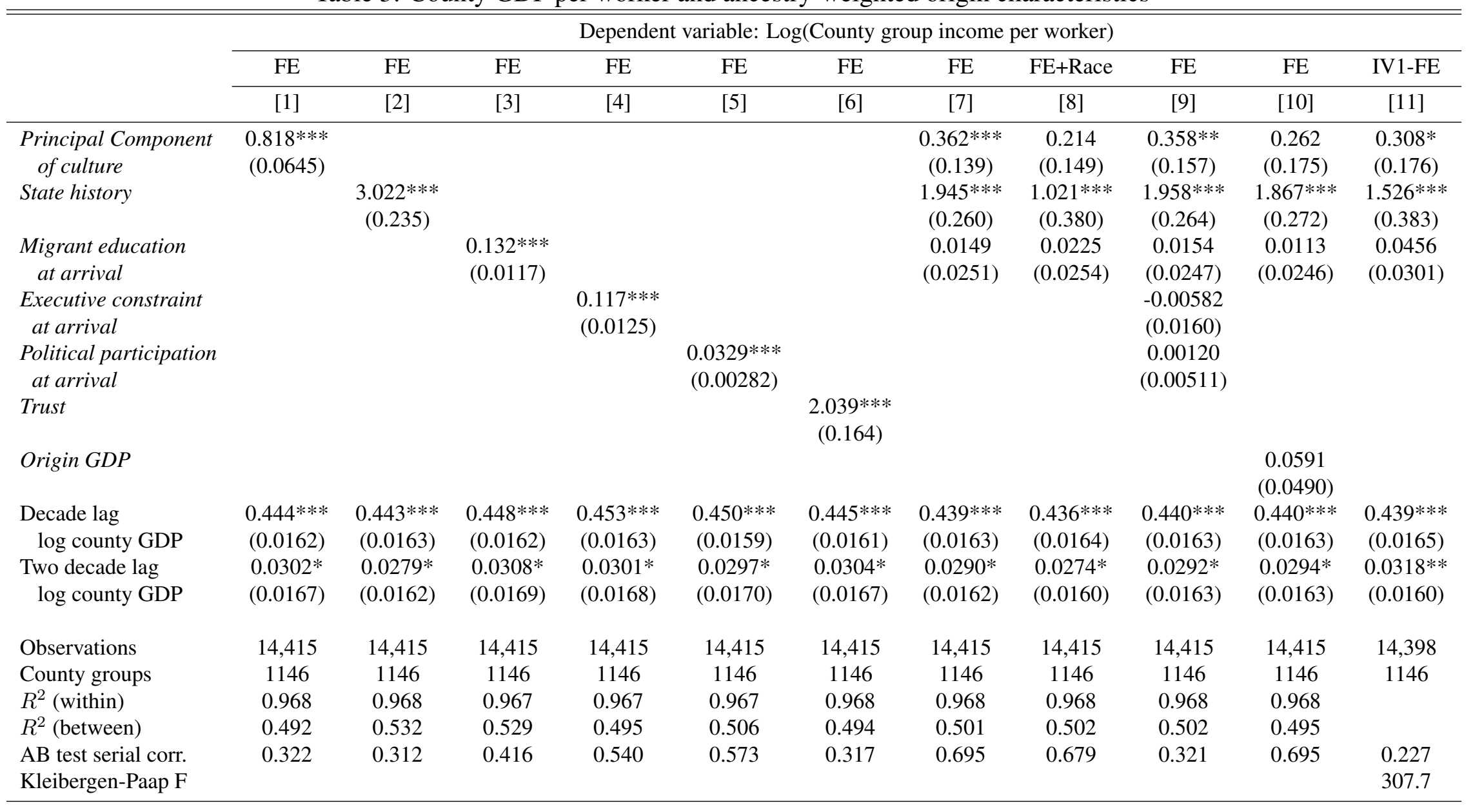

Notes: This table examines which of multiple possible endowments from the origin country matter for county GDP. Column 8 includes the fraction African American and Native American separately (the coefficients are not reported). IV1-FE in column 10 uses instruments constructed using ancestry in the previous decade growing at the national growth rate excluding the county's state (Approach 1 in Section 5.3.2). The AB test is the p-value for the Arellano and Bond (1991) test for second order serial correlation of the errors in difference. All regressions include census division by year fixed effects, county-group fixed effects, and standard errors are clustered at the county group level. Sources for origin variables are in the online appendix D. $* * * \mathrm{p}<0.01, * * \mathrm{p}<0.05,{ }^{*} \mathrm{p}<0.1$. 
not over-interpret them to conclude that these are the only endowments that matter. Still, when our summary measure, Origin GDP, is included with measures of culture, human capital and institutions in column 10, it is not significant and small, and the results do not change for Principal component of culture and State history in 1500. It appears that these measures of endowments, albeit imperfect, capture the different dimensions of economically significant endowments fairly well.

When we instrument using Approach 1, we obtain very similar results (compare column 11 with 7) and both the coefficients of Principal component of culture and State history remain significant. When using Approach 2 (not shown in table) only the coefficient of the Principal component of culture is significant in the general equation (all instrumented endowments are significant when included one at the time). When using GMM (Approach 3, not shown), none of the variables is significant, but the coefficients on Principal component of culture and State history are significant when included one at a time.

\subsection{The positive and negative impact of diversity}

Until now we have examined the effect on county-level GDP per worker of the ancestry-weighted average of the attributes people in a county brought from their respective origin countries. However, the diversity of ancestries may be as important for local development as the average of those attributes. We use several measures of diversity. One is the standard fractionalization index that measures the probability that any two individuals chosen from a population will not be of the same group:

$$
\operatorname{frac}_{c, t}=1-\sum_{a=1}^{A}\left(\pi_{c t}^{a}\right)^{2} .
$$

(Recent work has generalized this index by allowing it to incorporate measures of distance between groups (Bossert, D’Ambrosio, and La Ferrara, 2011). Weighted fractionalization measures how far groups are from each other on average along a particular dimension. The generalized fractionalization index is: 


$$
\operatorname{frac}_{c, t}^{w}=1-\sum_{j=1}^{A} \sum_{k=1}^{A} \pi_{c t}^{j} \pi_{c t}^{k} s_{t}^{j k},
$$

where the $w$ stands for a "weighted" fractionalization and $s^{j k}$ is a measure of similarity between countries of origin. ${ }^{25}$ The standard fractionalization index is just the weighted fractionalization index when members of different groups are assumed to be completely dissimilar ( $s^{j k}=0$ for $i \neq j$ ). While race is part of ancestry, race may have an independent effect. We emphasize again that while ancestry has an objective definition, race is a social construct, so the appropriate way to include race is not obvious. We create two variables that capture the racial component of fractionalization from African American and Native American ancestries. ${ }^{26}$ Because of the additive nature of fractionalization and its generalization, these variables allow the fractionalization coming from race to have an effect that is different from the overall effect of ancestry fractionalization.

Table 4 reports the results when we include measures of fractionalization. Column 1 shows the fixed-effects estimates, including fractionalization, origin-GDP-weighted fractionalization, and Origin GDP. The coefficient of Origin GDP remains significant. The coefficient of fractionalization is positive and significant, while the coefficient of origin-GDP-weighted fractionalization is negative and significant. ${ }^{27}$ Going from the 25 th to the 75 th percentile for fractionalization is associated with a rise in GDP per worker on impact of almost 10\% while going from the 25th to the 75th percentile of origin-GDP-weighted fractionalization reduces GDP per worker by almost 5\% (see the summary statistics in the online appendix Table A-2). The long run effects are approximately twice as large. The results are essentially unaltered when we instrument for the weighted endow-

\footnotetext{
${ }^{25}$ The definition of $s^{j k}$ is based on the difference of some country-of-origin measure $z$ between group $j$ and group $k$ as $s_{t}^{j k}=1-\left|z^{j}-z^{k}\right| / r$, where $r=\max _{j \in\{1 \ldots A\}} z^{j}-\min _{j \in\{1 \ldots A\}} z^{j}$ is the range of values that $z$ can take. As two groups become more similar along the $z$ dimension, their similarity approaches 1 .

${ }^{26}$ One is simply racial fractionalization: $\operatorname{frac}_{c, t}^{R}=1-\sum_{a \in\{A A, N A\}}\left(\pi_{c t}^{a}\right)^{2}$. The other is weighted fractionalization which is the difference of the racial ancestries from all other ancestries: $\operatorname{frac}_{c, t}^{w R}=1-$ $\sum_{r \in\{A A, N A\}}\left(\sum_{k=1}^{A} \pi_{c t}^{r} \pi_{c t}^{k} s_{t}^{r, k}+\sum_{j=1}^{A} \pi_{c t}^{j} \pi_{c t}^{r} s_{t}^{j, r}\right)$. Note that both $\operatorname{frac}_{c, t}^{R}$ and $\operatorname{frac}_{c, t}^{w R}$ are just the elements of regular fractionalization $\operatorname{frac}_{c, t}$ and weighted fractionalization $\operatorname{frac}_{c, t}^{w R}$ that have an African American or Native American ancestry.

${ }^{27}$ We have explored allowing for a quadratic term in fractionalization and weighted fractionalization. In our preferred dynamic specification, the quadratic term is not significant, and we have not found an internal optimum in any specification and so do not report these results.
} 
Table 4: County GDP per worker and diversity

\begin{tabular}{|c|c|c|c|c|c|c|}
\hline & \multicolumn{6}{|c|}{ Dep. Variable: Log(County group income per worker) } \\
\hline & $\mathrm{FE}$ & IV1-FE & IV2-FE & $\mathrm{FE}$ & FE+Race & IV1-FE \\
\hline & [1] & [2] & [3] & [4] & [5] & [6] \\
\hline Fractionalization & $\begin{array}{l}0.435 * * * \\
(0.0777)\end{array}$ & $\begin{array}{l}0.426 * * * \\
(0.102)\end{array}$ & $\begin{array}{c}1.649 * * * \\
(0.255)\end{array}$ & $\begin{array}{l}0.438 * * * \\
(0.0940)\end{array}$ & $\begin{array}{l}0.457 * * * \\
(0.105)\end{array}$ & $\begin{array}{c}0.409 * * * \\
(0.127)\end{array}$ \\
\hline Race Fractionalization & & & & & $\begin{array}{l}-0.0829 \\
(0.449)\end{array}$ & \\
\hline $\begin{array}{l}\text { Origin GDP weighted } \\
\text { fractionalization }\end{array}$ & $\begin{array}{c}-0.477 * * \\
(0.191)\end{array}$ & $\begin{array}{c}-0.589 * * \\
(0.233)\end{array}$ & $\begin{array}{c}-2.777 * * * \\
(0.477)\end{array}$ & & & \\
\hline Origin $G D P$ & $\begin{array}{l}0.283 * * * \\
(0.0342)\end{array}$ & $\begin{array}{l}0.288 * * * \\
(0.0424)\end{array}$ & $\begin{array}{c}0.0427 \\
(0.0692)\end{array}$ & & & \\
\hline $\begin{array}{l}\text { Migrant education } \\
\text { at arrival }\end{array}$ & & & & $\begin{array}{c}0.0394 \\
(0.0286)\end{array}$ & $\begin{array}{c}0.0267 \\
(0.0354)\end{array}$ & $\begin{array}{l}0.0698 * * \\
(0.0334)\end{array}$ \\
\hline $\begin{array}{l}\text { Principal Component } \\
\text { of culture }\end{array}$ & & & & $\begin{array}{l}0.298^{* *} \\
(0.135)\end{array}$ & $\begin{array}{l}0.283^{*} \\
(0.148)\end{array}$ & $\begin{array}{c}0.205 \\
(0.177)\end{array}$ \\
\hline State history & & & & $\begin{array}{c}1.012 * * * \\
(0.322)\end{array}$ & $\begin{array}{l}0.750^{*} \\
(0.445)\end{array}$ & $\begin{array}{l}0.771 * \\
(0.465)\end{array}$ \\
\hline $\begin{array}{l}\text { Education weighted } \\
\text { fractionalization }\end{array}$ & & & & $\begin{array}{c}0.944 * * \\
(0.411)\end{array}$ & $\begin{array}{c}0.551 \\
(0.464)\end{array}$ & $\begin{array}{c}0.725 \\
(0.491)\end{array}$ \\
\hline $\begin{array}{l}\text { P.C culture weighted } \\
\text { fractionalization }\end{array}$ & & & & $\begin{array}{c}-1.058 * * * \\
(0.323)\end{array}$ & $\begin{array}{c}-0.808 * * \\
(0.348)\end{array}$ & $\begin{array}{c}-0.950 * * \\
(0.440)\end{array}$ \\
\hline $\begin{array}{l}\text { State history weighted } \\
\text { fractionalization }\end{array}$ & & & & $\begin{array}{c}-0.495^{* * *} \\
(0.162)\end{array}$ & $\begin{array}{c}-0.546 * * * \\
(0.159)\end{array}$ & $\begin{array}{l}-0.360^{*} \\
(0.200)\end{array}$ \\
\hline $\begin{array}{l}\text { Race Education weighted } \\
\text { fractionalization }\end{array}$ & & & & & $\begin{array}{l}5.420 * * * \\
(2.064)\end{array}$ & \\
\hline $\begin{array}{l}\text { Race P.C culture weighted } \\
\text { fractionalization }\end{array}$ & & & & & $\begin{array}{c}-5.024 * * * \\
(1.943)\end{array}$ & \\
\hline $\begin{array}{l}\text { Race State history weighted } \\
\text { fractionalization }\end{array}$ & & & & & $\begin{array}{c}0.729 \\
(1.436)\end{array}$ & \\
\hline Observations & 14,415 & 14,398 & 13,232 & 14,415 & 14,408 & 14,398 \\
\hline County groups & 1146 & 1146 & 1023 & 1146 & 1146 & 1146 \\
\hline$R^{2}$ (within) & 0.968 & & & 0.968 & 0.968 & \\
\hline$R^{2}$ (between) & 0.539 & & & 0.548 & 0.548 & \\
\hline $\mathrm{AB}$ test serial corr. & 0.500 & 0.758 & 0.968 & 0.724 & 0.628 & 0.613 \\
\hline Kleibergen-Paap F & & 823.1 & 78.09 & & & 118.1 \\
\hline
\end{tabular}

Notes: This table examines whether diversity of ancestry or ancestry attributes matters for log county GDP per worker. The creation of fractionalization and weighted fractionalization is described in Section 5.4. All regressions include Division-Year, county fixed effects and two lags of log GDP per worker (sum of lags approximately .46 in all cases). The column with race (column 5) includes the fraction African American and Native American (coefficients not shown and not significant), racial fractionalization, attribute-weighted racial fractionalization (see footnote 26) IV1-FE uses Approaches 1 described in Section 5.3.2.The AB test is the p-value for the Arellano and Bond (1991) test for second order serial correlation of the errors in difference. All regressions include census division by year fixed effects, and standard errors cluster at the county group level. ${ }^{* * *} \mathrm{p}<0.01, * * \mathrm{p}<0.05, * \mathrm{p}<0.1$. 
ment variable, fractionalization, and origin-GDP-weighted fractionalization using either Approach 1 or 2 (see columns 2 and 3). Fractionalization seems to be the relevant measure of diversity. When we include polarization, it does not seem to have an independent effect, so we do not show this regression separately. ${ }^{28}$

We replace ancestry-weighted Origin GDP with our deep endowment variables and OriginGDP-weighted fractionalization with attribute-weighted fractionalization created from the distinct endowment variables in Table 4 columns 4 through 6. The Principal component of culture and State history remain positive and significant. The coefficients on culture-weighted fractionalization and State history fractionalization are negative and significant at the $1 \%$ level. The negative sign suggests that fractionalization of these attributes is particularly problematic. Ancestry fractionalization continues to have a positive effect on local development, and its coefficient is highly significant. Education-weighted fractionalization is also positive. We explore whether these effects are capturing skill diversity in the next section.

In column 5 of Table 4, we include as additional regressors the fraction of African Americans and the fraction of Native Americans, as well as racial fractionalization and attribute-weighted race fractionalization for our three origin attributes. The additional fractionalization variables represents the extra effect of diversity that comes along these two racial lines (see footnote 26). The results suggest that our main results still largely hold. The ancestry fractionalization coefficient is still positive, significant, and nearly the same size. Meanwhile, the extra component of race fractionalization is not significant or large. The coefficient on the ancestry-weighted culture and State history remain positive and significantat the $10 \%$ level. Similarly, the coefficients on cultureweighted fractionalization and State history-weighted fractionalization are negative, significant, and the same size. The additional racial fractionalization component for education is positive and significant, and the racial component of cultural fractionalization is negative and significant, sug-

\footnotetext{
${ }^{28}$ Polarization measures how far a county is from being composed of only two equally sized groups. Ager and Brückner (2013) found that polarization was negatively related to economic growth across counties in the US from 1870 to 1920 , while fractionalization was positively related to growth. Their measures of polarization and fractionalization are calculated by dividing the population into first-generation immigrants from different countries, African Americans, and all second- or higher- generation whites together. Our calculations treat ancestry groups as distinct even past the first generation.
} 
gesting that an important component of education and culture fractionalization is coming through race. This suggests that the diversity due to race has an additional impact on local development beyond differences in ancestry, but that the effect of racial diversity as well as of ancestry diversity is not necessarily negative.

Instrumenting the separate endowments and their diversity when they are all included together leads to much less precise results, especially for Approach 2. Approach 1, still yields significant coefficients for fractionalization culture-weighted fractionalization and State history-weighted fractionalization, as well as for weighted migrant education, that for the first time is significant when included with all the other endowments. It is not a surprise that the instruments do not capture second moments well. Even small differences between the instrument and the actual ancestry are magnified by squaring to form fractionalization, so the instrument caries far less information about the second moment.

These results capture different effects of diversity. The positive effect of fractionalization is consistent with the notion that it is beneficial for people with new skills, knowledge, and ideas to come into a county. Moreover, if they bring different tastes, the newcomers may open up new opportunities for trade. Yet, if those new groups are substantially different along important dimensions, such as level of development of the country of origin or culture, these differences may create conflict and prevent agreement on growth enhancing policies at the local level. Our results suggest that the effect of diversity depends on the dimension one emphasizes and thus help account for the different results obtained by the rich literature on diversity we discussed in the introduction.

\section{Mechanisms}

In this section, we explore some of the mechanisms through which ancestry endowments may affect county GDP. This investigation is hampered by the limited availability of panel data over long periods of time, so we consider this investigation as primarily suggesting directions for future research. We focus on three variables that are available at the county level for our sample period and capture possible mechanisms: county education, to understand whether ancestry works 
through human capital formation; voter participation as a proxy for social capital; and an index of occupational variety that gives us insight into the diversity of skills present in a county.

The results in Table 5 suggest that origin characteristics, summarized by Origin GDP, are strongly positively related to county education (see column 1, which shows the results for the basic dynamic model estimated with fixed effects). Before 1940 the census provides only information about literacy, whereas information on years of education is available from 1940. We use literacy rates to extend backwards the series for average years of education in a county. The effect of origin characteristics on local education is likely to be both direct and indirect: people from richer countries are likely both to be more educated and more likely to be interested in and willing to support local education. Having a more educated population is associated with higher county GDP per worker (column 2). Including both Origin GDP and education at the county level in the same regression helps us understand how much ancestry operates through the mechanism of improving education. If ancestry, summarized by Origin GDP, operates through improved education, then its coefficient should be smaller since we are controlling for the education channel. The estimated effect of Origin GDP remains significant and is only marginally smaller when county education is included, while the effect of county education is significant at the $10 \%$ level with a $t$ statistics of 1.89 (column 3). When we enter literacy rates and average years of education separately in the equation (column 4), the coefficient of literacy rates is highly significant, while the one for average years of education is not significant. The Origin GDP coefficient now decreases by $16 \%$. These results suggest that while Origin GDP does indeed improve county education, education is probably not the main channel through which it affects county GDP, although there is evidence that literacy rates were an important contributor to early local development. ${ }^{29}$

Increases in Origin GDP are also positively related to county voter participation which may be a proxy for social capital or civic engagement. Yet voter participation may also reflect de jure or de facto limitations to the voting process. Origin GDP is positively and significantly associated with voter participation (Table 5, column 5). Voter turnout, in turn, is positively and significantly

\footnotetext{
${ }^{29}$ On the importance of human capital for regional development see Gennaioli et al. (2014).
} 
related to county GDP per worker (column 6), although the decrease in the coefficient of Origin $G D P$ when both are included is small (column 7). Therefore, this particular proxy for social capital appears to play a relatively minor role in the transmission of the origin country attributes.

Finally, we explore one possible explanation for the positive effect of fractionalization: that greater ancestry fractionalization might bring with it a richer skill mix. We construct a measure of skill variety by using the occupational data from the individual census records. We divide occupations into either 10 or 82 categories. To capture the variety of skills available in a county, we construct a Constant Elasticity of Substitution (CES) aggregate of the occupations in each county. We impute the distributional share parameter and the elasticity of substitution between different skills using the full distribution of wages in 1940. We discuss our construction of the index in the online appendix F. 
Table 5: Ancestry and county GDP per worker: Mechanisms

\begin{tabular}{|c|c|c|c|c|c|c|c|}
\hline \multirow[t]{3}{*}{ Dependent variable: } & \multirow{2}{*}{$\begin{array}{c}\begin{array}{c}\text { County } \\
\text { Education }\end{array} \\
\text { FE }\end{array}$} & \multicolumn{3}{|c|}{$\begin{array}{l}\log (\text { county GDP } \\
\text { per worker) }\end{array}$} & \multirow{2}{*}{$\begin{array}{c}\begin{array}{l}\text { County voter } \\
\text { participation }\end{array} \\
\text { FE }\end{array}$} & \multicolumn{2}{|c|}{$\begin{array}{l}\log \text { (county GDP } \\
\text { per worker) }\end{array}$} \\
\hline & & $\mathrm{FE}$ & $\mathrm{FE}$ & $\mathrm{FE}$ & & $\mathrm{FE}$ & $\mathrm{FE}$ \\
\hline & [1] & {$[2]$} & {$[3]$} & [4] & [5] & [6] & [7] \\
\hline Origin GDP & $\begin{array}{l}0.727 * * * \\
(0.0550)\end{array}$ & & $\begin{array}{l}0.309 * * * \\
(0.0272)\end{array}$ & $\begin{array}{l}0.285 * * * \\
(0.0444)\end{array}$ & $\begin{array}{l}0.0736^{* * * *} \\
(0.00452)\end{array}$ & & $\begin{array}{l}0.309 * * * \\
(0.0241)\end{array}$ \\
\hline County education & & $\begin{array}{c}0.0302 * * * \\
(0.00750)\end{array}$ & $\begin{array}{l}0.00973 * \\
(0.00514)\end{array}$ & & & & \\
\hline $\begin{array}{c}\text { County literacy } \\
\text { (before 1940) }\end{array}$ & & & & $\begin{array}{l}0.280 * * * \\
(0.0984)\end{array}$ & & & \\
\hline $\begin{array}{l}\text { County years educ. } \\
\text { (1940 and after) }\end{array}$ & & & & $\begin{array}{l}-0.00644 \\
(0.00780)\end{array}$ & & & \\
\hline $\begin{array}{l}\text { Decade lag County voter } \\
\text { participation }\end{array}$ & & & & & & $\begin{array}{l}0.237 * * * \\
(0.0406)\end{array}$ & $\begin{array}{l}0.153 * * * \\
(0.0389)\end{array}$ \\
\hline $\begin{array}{l}\text { Decade lag } \\
\text { dependent variable }\end{array}$ & $\begin{array}{l}0.698 * * * \\
(0.0121)\end{array}$ & $\begin{array}{l}0.454 * * * \\
(0.0165)\end{array}$ & $\begin{array}{l}0.443 * * * \\
(0.0164)\end{array}$ & $\begin{array}{l}0.442 * * * \\
(0.0164)\end{array}$ & $\begin{array}{l}0.647 * * * \\
(0.0184)\end{array}$ & $\begin{array}{l}0.458 * * * \\
(0.0167)\end{array}$ & $\begin{array}{l}0.438 * * * \\
(0.0168)\end{array}$ \\
\hline $\begin{array}{l}\text { Two Decade lag } \\
\text { dependent variable }\end{array}$ & $\begin{array}{l}-0.0441 * * * \\
(0.0105)\end{array}$ & $\begin{array}{c}0.0274 \\
(0.0184)\end{array}$ & $\begin{array}{l}0.0279^{*} \\
(0.0166)\end{array}$ & $\begin{array}{l}0.0284 * \\
(0.0165)\end{array}$ & $\begin{array}{l}0.0284 * * \\
(0.0138)\end{array}$ & $\begin{array}{c}0.0501 * * * \\
(0.0133)\end{array}$ & $\begin{array}{c}0.0484 * * * \\
(0.0127)\end{array}$ \\
\hline Observations & 14,549 & 14,422 & 14,415 & 14,415 & 14,179 & 14,253 & 14,250 \\
\hline County groups & 1149 & 1146 & 1146 & & 1145 & 1145 & 1145 \\
\hline$R^{2}$ (within) & 0.985 & 0.967 & 0.968 & 0.968 & 0.903 & 0.968 & 0.969 \\
\hline$R^{2}$ (between) & 0.633 & 0.678 & 0.501 & 0.376 & 0.695 & 0.650 & 0.515 \\
\hline AB test serial corr. & 0.00276 & 0.524 & 0.304 & 0.226 & 0 & 0.697 & 0.821 \\
\hline
\end{tabular}

Notes: This table shows other possible outcomes that may explain the relationship between ancestry and log county GDP per worker. County education is a variable constructed from county literacy before 1940 and years of education after. We use a regression of county literacy in 1930 on years of education in 1940 to convert pre-1940 literacy into projected years of education, so county education is in units of years of education. Voter participation is the share of vote in the most recent presidential election relative to the entire population (including women and African Americans who were disenfranchised for much of the period). County voter participation is compiled from IPUMS study 1 and 13, and CQ Press Voting and Elections Data. All regressions are estimated using county-group fixed effects, have census division $\mathrm{X}$ year fixed effects, and allow the standard errors to be clustered at the county-group level. 
As shown in Table 6, for a reasonable range of elasticities of substitution and for both the broad and narrow occupational classifications, ancestry fractionalization is positively correlated with occupational variety and negatively correlated with origin-GDP-weighted fractionalization, controlling for Origin GDP (columns 1 and 3). Moreover, the index of occupational variety is positively and significantly related to county GDP when we include it in our standard equation containing Origin GDP and fractionalization (columns 2 and 4). The coefficient of ancestry fractionalization is smaller and less significant relative to its value in the basic specification of Table 4, column 1 . The results suggest that the positive effect of ancestry fractionalization reflects, at least in part, the richer mix of skills associated with a county's increasing degree of ancestry diversity. The positive sign of the coefficient of education weighted fractionalization may also capture this effect.

\section{Conclusion}

The endowments brought by immigrants matter for economic development. Over the long term, counties with ancestry groups coming from countries at a higher level of development are more productive. The effects build over several decades, suggesting that new immigrants take some time to make their mark on their new homes. Cultural traits that enhance immigrant's ability to interact with others (such as trust) and coming from a country with a long history of centralized and independent government appear to be the most important explanations for the impact of ancestry. Ancestry diversity also improves productivity, while diversity in the cultural values reduces it. It seems that when groups have to share a place and work together, diversity is good, as long as there is a degree of agreement in terms of cultural attitudes that facilitate exchange, production, and the ability to agree in the public sphere.

The complex mosaic of ancestry in the United States has changed profoundly over time, and it is still evolving as new immigrants come and people move internally. Our results provide novel evidence also on the fundamental and recurring question of whether the United States acts as a "melting pot," quickly absorbing new immigrant groups, or whether immigrant groups maintain 
Table 6: Ancestry, occupational mix, and county GDP per worker

\begin{tabular}{lcccc}
\hline \hline Dependent variable: & $\begin{array}{c}\text { Occ. Mix } \\
\text { (broad, } \sigma=1.5)\end{array}$ & $\begin{array}{c}\log (\mathrm{GDP} \\
\mathrm{p} . \mathrm{w} .)\end{array}$ & $\begin{array}{c}\text { Occ. Mix } \\
\text { (narrow, } \sigma=2)\end{array}$ & $\begin{array}{c}\log (\mathrm{GDP} \\
\mathrm{p} . \mathrm{w} .)\end{array}$ \\
\cline { 2 - 5 } & {$[1]$} & {$[2]$} & {$[3]$} & {$[4]$} \\
\hline Origin GDP & $0.00488^{* * *}$ & $0.274^{* * *}$ & $0.00101^{* * *}$ & $0.260^{* * *}$ \\
& $(0.00123)$ & $(0.0478)$ & $(0.000222)$ & $(0.0376)$ \\
Fractionalization & $0.00864 * *$ & $0.179^{* *}$ & $0.00212^{* * *}$ & 0.0761 \\
& $(0.00356)$ & $(0.0823)$ & $(0.000787)$ & $(0.0787)$ \\
Origin GDP weighted & $-0.0203 * *$ & 0.251 & $-0.00509 * *$ & $0.427 *$ \\
fractionalization & $(0.00963)$ & $(0.210)$ & $(0.00190)$ & $(0.235)$ \\
Occupation Mix & & $5.370^{* * *}$ & & \\
(broad, $\sigma=1.5$ & & $(0.412)$ & & \\
Occupation Mix & & & & $27.22 * * *$ \\
(narrow, $\sigma=2)$ & & & & $(2.436)$ \\
Decade lag & $0.741 * * *$ & $0.397 * * *$ & $0.707 * * *$ & $0.390^{* * *}$ \\
dependent variable & $(0.0252)$ & $(0.0251)$ & $(0.0225)$ & $(0.0283)$ \\
Two Decade lag & 0.0285 & $0.0369^{*}$ & $0.0487 * *$ & 0.0345 \\
dependent variable & $(0.0206)$ & $(0.0207)$ & $(0.0183)$ & $(0.0212)$ \\
& & & & \\
Observations & 14,179 & 14,250 & 14,250 & 14,216 \\
Division X Year & Yes & Yes & Yes & Yes \\
County group FE & Yes & Yes & Yes & Yes \\
County groups & 1145 & 1145 & 1145 & 1145 \\
$R^{2}$ (within) & 0.835 & 0.968 & 0.969 & 0.968 \\
$R^{2}$ (between) & 0.625 & 0.324 & 0.139 & 0.259 \\
AB test serial corr. & 0.332 & 0.514 & 0.166 & 0.144 \\
\hline
\end{tabular}

Notes: This table shows the relationship between log county GDP per worker, the county occupation mix, and ancestryweighted Origin GDP. The occupational mix in a county is measured as the Constant Elasticity of Substitution Aggregator with the elasticity $\sigma$ and weights determined by the relative wages within occupations in 1940 (see the online appendix $\mathrm{F}$ for the creation of the CES aggregator). Broad occupations are the first digit of the IPUMS codes, resulting in 10 categories, while narrow occupations are more detailed, resulting in 82 occupational categories after dropping the non-occupational response. All regressions include county group fixed effects and division-by-year effects, and they cluster standard errors at the county-group level. 
distinct identities in at least some dimensions. The significance and persistence of our ancestry measure's effect are difficult to explain in a pure assimilationist view and are more consistent with approaches that emphasize a degree of persistence of traits across generations. Our results show that this process generates important long-run consequences for local economic development. 


\section{References}

Abramitzky, Ran and Leah Boustan. 2017. "Immigration in American Economic History.” Journal of Economic Literature 55 (4):1311-45.

Abramitzky, Ran, Leah Boustan, and Katherine Eriksson. 2020. "Do Immigrants Assimilate More Slowly Today Than in the Past?" American Economic Review: Insights 2 (1):125-41.

Abramitzky, Ran, Leah Platt Boustan, and Katherine Eriksson. 2012. "Europe's Tired, Poor, Huddled Masses: Self-Selection and Economic Outcomes in the Age of Mass Migration." American Economic Review 102 (5):1832-56.

Abrigo, Michael R.M. and Inessa Love. 2015. "Estimation of panel vector autoregression in Stata: A package of programs." Working paper, University of Hawaii. Available: https: / / sites . google.com/a/hawaii.edu/inessalove/home/pvar, accessed 24 July 2015.

Acemoglu, Daron, Simon Johnson, and James Robinson. 2005. "Institutions as the Fundamental Cause of Long-Run Growth." In Handbook of Economic Growth, vol. 1A, edited by Philippe Aghion and Steven Durlauf. Elsevier, 385-472.

Acemoglu, Daron, Simon Johnson, and James A. Robinson. 2001. “The Colonial Origins of Comparative Development: An Empirical Investigation.” American Economic Review 91 (5):1369_ 1401.

Ager, Philipp and Markus Brückner. 2013. "Cultural diversity and economic growth: Evidence from the US during the age of mass migration." European Economic Review 64:76-97.

Albouy, David Y. 2012. "The Colonial Origins of Comparative Development: An Empirical Investigation: Comment.” American Economic Review 102 (6):3059-3076.

Alesina, Alberto, Reza Baqir, and William Easterly. 1999. "Public Goods and Ethnic Divisions." The Quarterly Journal of Economics 114 (4):1243-1284.

Alesina, Alberto and Paola Giuliano. 2015. "Culture and Institutions." Journal of Economic Literature 53 (4):898-944.

Alesina, Alberto, Johann Harnoss, and Hillel Rapoport. 2016. "Birthplace Diversity and Economic Prosperity." Journal of Economic Growth 21:101-138.

Alesina, Alberto, Stelios Michalopoulos, and Elias Papaioannou. 2016. "Ethnic Inequality." Journal of Political Economy 124 (2):428-488.

Algan, Yann and Pierre Cahuc. 2010. "Inherited Trust and Growth." The American Economic Review 100 (5):2060-2092.

Arellano, Manuel and Stephen Bond. 1991. "Some Tests of Specification for Panel Data: Monte Carlo Evidence and an Application to Employment Equations." The Review of Economic Studies 58 (2):277-297. 
Ashraf, Quamrul and Oded Galor. 2013. "The 'Out of Africa' Hypothesis, Human Genetic Diversity, and Comparative Economic Development.” American Economic Review 103 (1):1-46.

Bandiera, Oriana, Myra Mohnen, Imran Rasul, and Martina Viarengo. 2019. "Nation-building Through Compulsory Schooling during the Age of Mass Migration." The Economic Journal 129:62-109.

Bartel, Ann P. 1989. "Where Do the New U.S. Immigrants Live?” Journal of Labor Economics 7 (4):371-91.

Bartik, Timothy J. 1991. Who Benefits from State and Local Economic Development Policies? Kalamazoo, MI: W.E. Upjohn Institute for Employment Research.

Baum-Snow, Nathaniel. 2007. "Did highways cause suburbanization?" The Quarterly Journal of Economics 122 (2):775-805.

Bisin, Alberto and Thierry Verdier. 2011. "The Economics of Cultural Transmission and Socialization." In Handbook of Social Economics, vol. 1A, edited by Matthew O. Jackson and Alberto Bisin. Elsevier, 339-416.

Bockstette, Valerie, Areendam Chanda, and Louis Putterman. 2002. "States and Markets: The Advantage of an Early Start.” Journal of Economic Growth 7 (4):347-69.

Borcan, Oana, Ola Olsson, and Louis Putterman. 2018. "State history and economic development: evidence from six millennia." Journal of Economic Growth 23:1-40.

Borjas, George J. 1987. "Self-Selection and the Earnings of Immigrants." The American Economic Review 77 (4):531-553. 1717.

Borjas, George J. 2014. Immigration economics. Cambridge, MA: Harvard University Press.

Bossert, Walter, Conchita D'Ambrosio, and Eliana La Ferrara. 2011. "A Generalized Index of Fractionalization." Economica 78 (312):723-750.

Burchardi, Konrad B, Thomas Chaney, and Tarek A Hassan. 2018. "Migrants, Ancestors, and Foreign Investments." The Review of Economic Studies 86 (4):1448-1486.

Card, David. 2001. "Immigrant Inflows, Native Outflows, and the Local Labor Market Impacts of Higher Immigration.” Journal of Labor Economics 19 (1):22-64.

Daniels, Roger. 2002. Coming to America. New York: HarperPerennial.

Desmet, Klaus, Ignacio Ortuño-Ortín, and Romain Wacziarg. 2017. "Culture, Ethnicity, and Diversity." American Economic Review 107 (9):2479-2513.

Docquier, Fréd'eric, Riccardo Turati, Jérôme Valette, and Chrysovalantis Vasilakis. 2018. "Birthplace Diversity and Economic Growth: Evidence from the US States in the Post-World War II Period.” Discussion Paper Series 11802, IZA Institute of Labor Economics. 
Doepke, Matthias and Fabrizio Zilibotti. 2017. "Parenting With Style: Altruism and Paternalism in Intergenerational Preference Transmission.” Econometrica 85 (5):1331-1371.

Easterly, William and Ross Levine. 1997. "Africa's Growth Tragedy: Policies and Ethnic Divisions." The Quarterly Journal of Economics 112 (4):1203-1250.

- 2016. "The European origins of economic development." Journal of Economic Growth 21 (3):225-257.

Fernández, Raquel. 2010. “Does Culture Matter?” In Handbook of Social Economics, vol. 1A, edited by Matthew O. Jackson and Alberto Bisin. North Holland, The Netherlands: Elsevier, $481-510$.

Gennaioli, Nicola, Rafael La Porta, Florencio Lopez De Silanes, and Andrei Shleifer. 2014. "Growth in regions." Journal of Economic Growth 19 (3):259-309.

Gennaioli, Nicola and Ilia Rainer. 2007. "The Modern Impact of Precolonial Centralization in Africa." Journal of Economic Growth 12 (3):185-234.

Giavazzi, Francesco, Ivan Petkov, and Fabio Schiantarelli. 2019. "Culture: Persistence and Evolution." Journal of Economic Growth 24 (2):117-154.

Glaeser, Edward L., Rafael La Porta, Florencio Lopez de Silanes, and Andrei Shleifer. 2004. "Do Institutions Cause Growth?” Journal of Economic Growth 9 (3):271-303.

Guiso, Luigi, Paola Sapienza, and Luigi Zingales. 2006. "Does Culture Affect Economic Outcomes?" Journal of Economic Perspectives 20 (2):23-48.

Guiso, Luigi, Luigi Zingales, and Paola Sapienza. 2008. "Alfred Marshall Lecture: Social Capital as Good Culture." Journal of the European Economic Association 6 (2/3):295-320.

Hatton, Timothy James and Jeffrey G. Williamson. 1998. The Age of Mass Migration: Causes and Economic Impact. Oxford University Press.

Holtz-Eakin, Douglas, Whitney Newey, and Harvey S. Rosen. 1988. "Estimating Vector Autoregressions with Panel Data." Econometrica 56 (6):1371-1395.

Michalopoulos, Stelios. 2012. "The Origins of Ethnolinguistic Diversity." American Economic Review 102 (4):1508-1539.

Michalopoulos, Stelios and Elias Papaioannou. 2013. "Pre-Colonial Ethnic Institutions and Contemporary African Development." Econometrica 81 (1):113-152.

Miguel, Edward and Mary Kay Gugerty. 2005. "Ethnic diversity, social sanctions, and public goods in Kenya.” Journal of Public Economics 89 (11-12):2325-2368.

Nagel, Joane. 1994. "Constructing Ethnicity: Creating and Recreating Ethnic Identity and Culture." Social Problems 41 (1):152-176. 
Nickell, Stephen. 1981. "Biases in Dynamic Models with Fixed Effects." Econometrica 49 (6):1417-1426.

Nunn, Nathan. 2009. “The Importance of History for Economic Development.” Annual Review of Economics 1 (1):65-92.

Ottaviano, Gianmarco I. P. and Giovanni Peri. 2006. "The economic value of cultural diversity: Evidence from US cities." Journal of Economic Geography 6 (1):9-44.

— 2012. "Rethinking the Effect of Immigration on Wages." Journal of the European Economic Association 10 (1):152-197.

Peri, Giovanni. 2012. "The Effect of Immigration on Productivity: Evidence from U.S. States." Review of Economics and Statistics 94 (1):348-358.

Putterman, Louis and David N. Weil. 2010. "Post-1500 Population Flows and The Long-Run Determinants of Economic Growth and Inequality." The Quarterly Journal of Economics 125 (4):1627-1682.

Roodman, David. 2009. "How to do xtabond2: An introduction to difference and system GMM in Stata." Stata Journal 9 (1):86-136(51).

Sequeira, Sandra, Nathan Nunn, and Nancy Qian. 2019. "Immigrants and the Making of America." The Review of Economic Studies 87 (1):382-419.

Spolaore, Enrico and Romain Wacziarg. 2009. "The Diffusion of Development." The Quarterly Journal of Economics 124 (2):469-529.

— 2013. "How Deep Are the Roots of Economic Development?" Journal of Economic Literature 51 (2):325-69.

Sutch, Richard. 2006. Historical Statistics of the United States, Earliest Times to the Present: Millennial Edition, chap. Gross domestic product: 1790-2002 [Continuous annual series]. Cambridge University Press, Table Ca9-19.

Tabellini, Guido. 2010. "Culture and Institutions: Economic Development in the Regions of Europe." Journal of the European Economic Association 8 (4):677-716.

Tabellini, Marco. 2020. "Gifts of the Immigrants, Woes of the Natives: Lessons from the Age of Mass Migration.” Review of Economic Studies 87 (1):454-486.

Waters, Mary C. 1990. Ethnic Options: Choosing Identities in America. Berkeley, CA: University of California Press. 